\title{
1 ATP Binding Cassette Proteins ABCG37 and ABCG33 are required for potassium-independent cesium uptake in Arabidopsis roots
}

4 Mohammad Arif Ashraf $^{1}$, Sayaka Kumagai ${ }^{2}$, Keita Ito $^{2}$, Ryohei Sugita ${ }^{3}$, Keitaro Tanoi ${ }^{3,4}$, Abidur $5 \operatorname{Rahman}^{1,2,5^{*}}$

$6{ }^{1}$ United Graduate School of Agricultural Sciences, Iwate University, Morioka, 020-8550, Japan

$7 \quad{ }^{2}$ Faculty of Agriculture, Dept. of Plant Bio Sciences, Iwate University, Morioka, 020-8550,

8 Japan

$9{ }^{3}$ Graduate School of Agriculture and Life Sciences, The University of Tokyo, Tokyo, 113-8654, 10 Japan

$11{ }^{4}$ PRESTO, Japan Science and Technology Agency (JST), 4-1-8 Honcho, Kawaguchi, Saitama

12 332-0012, Japan

$13{ }^{5}$ Agri-Innovation Center, Iwate University, Morioka, 020-8550, Japan

14

15 *Corresponding author: email: abidur@iwate-u.ac.jp

16

17

18 


\section{Abstract}

27 Radiocesium, accumulated in the soil by nuclear accidents is a major environmental concern. The transport process of cesium $\left(\mathrm{Cs}^{+}\right)$is tightly linked to the indispensable plant nutrient

29 potassium $\left(\mathrm{K}^{+}\right)$as they both belong to the group I alkali metal with similar chemical properties.

30 Most of the transporters that had been characterized to date as $\mathrm{Cs}^{+}$transporters are directly or

31 indirectly linked to $\mathrm{K}^{+}$. Using a combinatorial approach of physiology, genetics, cell biology and

32 root uptake assay, here we identified two ATP-Binding Cassette (ABC) proteins, ABCG37 and

33 ABCG33 as facilitators of $\mathrm{Cs}^{+}$influx. The gain-of-function mutant of ABCG37 (abcg37-1)

34 showed hypersensitive response to $\mathrm{Cs}^{+}$-induced root growth inhibition, while the double knock

35 out mutant of ABCG33 and ABCG37 (abcg33-1abcg37-2) showed resistance. Single loss-of-

36 function mutant of ABCG33 and ABCG37 did not show any alteration in $\mathrm{Cs}^{+}$response. Short

37 term uptake experiment with radioactive $\mathrm{Cs}^{+}$revealed reduced $\mathrm{Cs}^{+}$uptake in abcg33-1abgc37-2

38 compared with wild type in presence or absence of $\mathrm{K}^{+}$. Potassium response and content were 39 unaffected in the double mutant background confirming that $\mathrm{Cs}^{+}$uptake by ABCG33 and 40 ABCG37 is independent of $\mathrm{K}^{+}$. Collectively, this work identified two ABC proteins as new $\mathrm{Cs}^{+}$ 41 influx carriers, which act redundantly and independent of $\mathrm{K}^{+}$uptake pathway. 


\section{Introduction}

54 One of the most dangerous contaminants generated in a nuclear accident is cesium $\left(\mathrm{Cs}^{+}\right)$, which 55 shares similar chemical properties with potassium $\left(\mathrm{K}^{+}\right)$. The stable isotope of cesium ${ }^{133} \mathrm{Cs}$ is 56 present at a very low concentration (less than $25 \mu \mathrm{g} / \mathrm{g}$ ) in the soil and does not possess any major

57 environmental concern (Cooghtrey et al., 1983). However, two radioisotopes of Cs $\left({ }^{134} \mathrm{Cs}\right.$ and ${ }^{137} \mathrm{Cs}$ ) are of environmental concerns due to their emission of harmful $\beta$ and $\gamma$ radiation, relatively long half-lives, and rapid incorporation into biological systems (White and Broadly, 2000, Kinoshita et al., 2011). In fact, consumption of agricultural product contaminated with radiocesium is the principal route of human exposure to this radionucleotide (Shaw and Bell, 1991), which has been shown to be related to increased risk of cancer. Trials of nuclear weapons, discharges from nuclear plants, and nuclear accidents such as the Chernobyl (Cooghtrey et al., 1983) and Fukushima incidents (Isaure et al., 2006) can result in large accumulation of radioactive $\mathrm{Cs}^{+}$in the ground. This radioactive $\mathrm{Cs}^{+}$is expected to be transmitted to the crops grown in the contaminated fields and cause serious health hazard for the population (Zhu and Smolders, 2000). For public health safety, the Japanese government restricted agricultural crop production on the soil containing more than $5000 \mathrm{~Bq} / \mathrm{kg}$ (Yamaki et al., 2017). Hence, decontamination of the soil is one of the major priorities to keep the crop fields clean from radio cesium for producing crops free of contamination.

Radiocesium mostly accumulates on the surface of the soil (Fujiwara, 2013). Removal of top soil and transport to dedicated sites is one of the potential solutions for cleaning radioactive $\mathrm{Cs}^{+}$contaminated field. Unfortunately, removal of soil from the surface, transportation and management is not an economic solution. Another technique is to use potassium fertilizer to reduce radiocesium toxicity (Zhu and Smolders, 2000). The classic work since 1940 suggest that $\mathrm{Cs}^{+}$uptake is regulated through both $\mathrm{K}^{+}$transporter and channels (Collander, 1941). Till today, most of the identified transporters that transport $\mathrm{Cs}^{+}$are already reported $\mathrm{K}^{+}$transporters. For instance, rice OsHAK1 (HIGH AFFINITY $\mathrm{K}^{+}$TRANSPORTER 1) and OsHAK5 which are known $\mathrm{K}^{+}$transporters can also function as cesium transporters (Nieves - Cordones et al., 2017; Rai et al., 2017). AtKUP/HAK/KT9 also functions as uptake carrier for potassium and cesium supplying more $\mathrm{K}^{+}$in the soil (Shaw and Bell, 1991). However, this strategy has major 
drawbacks; 1) the $\mathrm{K}^{+}$transporter functioning at low external potassium concentration shows little discrimination against $\mathrm{Cs}^{+}$, while the $\mathrm{K}^{+}$channel is dominant at high external $\mathrm{K}^{+}$concentration with high discrimination against $\mathrm{Cs}^{+}$(Zhu and Smolders, 2000), 2) high concentration of potassium itself is toxic to plants regardless of cesium concentration (Hampton et al., 2004), and 3 ) it is also economically impractical to provide large amount of potassium to soil. Further, it is a general consensus among the scientists that the mechanism by which $\mathrm{Cs}^{+}$is taken up by plant roots is not completely understood. $\mathrm{K}^{+}$transporters and channel are only partially responsible for $\mathrm{Cs}^{+}$uptake and translocation (Zhu and Smolders, 2000). Taken together, these results suggest that there are alternative routes for $\mathrm{Cs}^{+}$transport in plant which needs to be explored to understand the molecular mechanism of $\mathrm{Cs}^{+}$uptake.

One of the major pathways for plant to detoxify toxic metals is through transporting to sequestering them in the vacuole. The ATP binding cassette (ABC) transporters, also called multidrug resistance proteins, are ubiquitous in plant and animal kingdom and play an important role in transporting various substances, including metals. For instance, tonoplast-localized AtABCC1 and AtABCC2 transport As (Song et al., 2010), Cd, and Hg (Park et al., 2012) inside vacuole. AtATM3/AtABCB25 is involved in cadmium transport (Kim et al., 2006). Plasma membrane-localized AtABCG36/AtPDR8 functions as efflux carrier of Cd (Kim et al., 2007). AtABCG40 has been shown to be linked to lead transport (Lee et al., 2005). These results suggest that diverse substrates, including multiple metals can be efficiently transported by the ABC superfamily transporters.

Although $\mathrm{Cs}^{+}$has been suggested to compete with $\mathrm{K}^{+}$for translocation, transcriptome analysis revealed that distinct set of genes show altered expression in $\mathrm{Cs}^{+}$intoxicated plants compared with $\mathrm{K}^{+}$starved plants (Hampton et al., 2004), confirming that $\mathrm{Cs}^{+}$intoxication symptom in plants is not solely linked to $\mathrm{K}^{+}$. Interestingly, in $\mathrm{Cs}^{+}$intoxicated plants, genes encoding $\mathrm{ABC}$ proteins showed altered expression pattern. At least 4 genes belong to this family showed 2.5-3 fold upregulation in response to $\mathrm{Cs}^{+}$application but were not altered in $\mathrm{K}^{+}$ starvation (Hampton et al., 2004). In addition, a recent study using rice-transporter-enriched yeast expression library screening for $\mathrm{Cs}^{+}$carrier identified one $\mathrm{ABC}$ transporter and one NRAMP transporter as functional $\mathrm{Cs}^{+}$transporter in yeast (Yamaki et al., 2017). Taken together, 
112 these results suggest the possible existence of $\mathrm{K}^{+}$independent transport system of $\mathrm{Cs}^{+}$in plant 113 and also identify $\mathrm{ABC}$ proteins as potential targets functioning as $\mathrm{Cs}^{+}$transporters.

115 transport. In plants, there are 8 subfamilies of $\mathrm{ABC}$ transporter proteins, namely $\mathrm{ABCA}-\mathrm{ABCH}$ 116 (Verrier et al., 2008). The Arabidopsis ABC superfamily comprises of 130 full molecular 117 transporters containing at least two membrane spanning domains and two nucleotide binding 118 folds. Among the ABC protein subfamilies, subfamilies B, C, and G have already been shown to possess metal transport activity (Lee et al., 2005; Kim et al., 2006; Kim et al., 2007; Song et al., 2010; Park et al., 2012). ABCC proteins are exclusively tonoplast localized and ABCB and ABCG are predominantly plasma membrane localized (Verrier et al., 2008). Since we are interested in $\mathrm{Cs}^{+}$transport from soil, we focused on plasma membrane localized subfamilies (ABCB and $\mathrm{ABCG}$ ). Through screening of 37 available $\mathrm{ABCB}$ and $\mathrm{ABCG}$ mutants root growth against a concentarion of $\mathrm{Cs}^{+}(1.5 \mathrm{mM})$ which inhibits 50 percent root growth in wild type, we identified ABCG33 and ABCG37 as potential $\mathrm{Cs}^{+}$uptake carriers. The gain-of-function mutant of ABCG37 (abcg37-1) showed hypersensitive response to $\mathrm{Cs}^{+}$-induced root growth inhibition, while the double knock out mutant of ABCG33 and ABCG37 (abcg33-1abcg37-2) showed resistance. Single-loss-of function mutant of ABCG33 and ABCG37 (abcg33-1; abcg37-2) did not show any alteration in $\mathrm{Cs}^{+}$response. Short term uptake experiment with radioactive $\mathrm{Cs}^{+}$ revealed reduced cesium uptake by abcg33-1abgc37-2 compared with wild-type in presence or absence of $\mathrm{K}^{+}$. Potassium response and content were unaffected in the double mutant background confirming that $\mathrm{Cs}^{+}$uptake by ABCG33 and ABCG37 is independent of $\mathrm{K}^{+}$. Collectively, this work identified two $\mathrm{ABC}$ proteins as new $\mathrm{Cs}^{+}$uptake carriers, which act redundantly and independent of $\mathrm{K}^{+}$uptake pathway.

\section{Results}

\section{Cesium inhibits Arabidopsis primary root growth elongation}

Metal stress or toxicity in plants is sensed via plant root and subsequently transported to other parts of the plant. To understand the effect of $\mathrm{Cs}^{+}$on primary root growth, we performed both dose response and time course assay of $\mathrm{CsCl}$ using Arabidopsis wild-type (Col-0) seedlings.

140 The time course and dose response data indicate that $1 \mathrm{mM}$ and $1.5 \mathrm{mM}$ cesium inhibits root growth approximately $50 \%$ after five days and three days incubation, respectively (Figure 1A). 
142 Because $1.5 \mathrm{mM} \mathrm{Cs}^{+}$could inhibit $\sim 50 \%$ root growth in a shorter incubation period, we decided

143 to use $1.5 \mathrm{mM}$ cesium and three days incubation as an assay system for further experiments. This 144 treatment affects the growth of the whole seedling including root and leaf. After 3 day incubation 145 in $1.5 \mathrm{mM} \mathrm{Cs}^{+}$, root growth was inhibited and leaf chlorosis became apparent (Figures $1 \mathrm{~A}$ and 146 1B).

The growth of primary root is a combination of cell division and elongation, which is further extended through differentiation (Rahman et al., 2007).Cesium-induced inhibition of primary root growth could be the consequence of either decreased cell number or shorter cell length or both. To answer this question, $\mathrm{Cs}^{+}$treated seedlings were subjected to kinematic analysis (Rahman et al., 2007), which revealed that $\mathrm{Cs}^{+}$inhibits both cell elongation and cell production (Figures 1C and 1D). The $\mathrm{Cs}^{+}$effect on cell production rate was further confirmed by using G2-M phase cell cycle marker CyclinB1;1::GUS (Colón - Carmona et al., 1999), where only few cells were found to be mitotically active compared with the wild type (Figure 1E). The reduced cell division also affected the meristem growth as the reduction of meristem size was observed in $\mathrm{Cs}^{+}$treated seedlings (Figure 1E and 1F). Although root growth was severely inhibited and root phenotype drastically changed after 3 day $\mathrm{Cs}^{+}$incubation, the meristematic cells remain active as we did not observe any cell death by Propidium Iodide (PI) staining (Figure 1F).Taken together, these results suggest that cesium affects both cell division and elongation to inhibit the overall primary root elongation.

\section{Gain-of-function mutant $\operatorname{abcg37-1}$ is hypersensitive to cesium} have already been reported to transport metals such as $\mathrm{As}, \mathrm{Cd}, \mathrm{Hg}, \mathrm{Pb}$ (Lee et al., 2005; Kim et al., 2006; Kim et al., 2007; Song et al., 2010; Park et al., 2012). The broader substrate specificity along with the altered expression pattern of some of the $\mathrm{ABC}$ family proteins under $\mathrm{Cs}^{+}$ intoxicated condition (Hampton et al., 2004) make them potential candidates for $\mathrm{Cs}^{+}$transporter.

167 To elucidate the roles of $\mathrm{ABC}$ proteins in $\mathrm{Cs}^{+}$transport, we focused on plasma membrane localized subfamilies of $\mathrm{ABC}$ proteins $\mathrm{ABCB}$ and $\mathrm{ABCG}$ and screened available $20 \mathrm{ABCB}$ and 17 ABCG mutants against $1.5 \mathrm{mM}$ cesium for root growth response, which inhibits around $50 \%$ 170 root growth in wild-type (Supplemental Figures 1A and 1B). The screening revealed four 
172 interested in $\mathrm{Cs}^{+}$uptake from soil, out of these four mutants, we selected abcg37-1 (also known

173 as $p d r 9-1$ ) for further studies as it is a gain-of-function mutant (Ito and Gray, 2006), and showed

174 hypersensitive response to $\mathrm{Cs}^{+}$. Time course and dose response analyses revealed that $a b c g 37-1$

175 shows hypersensitive response to root growth at all concentrations and all incubation periods that

176 we tested (Supplemental Figure 2). The $\mathrm{Cs}^{+}$hypersensitivity in the gain of function mutant

177 suggests that $\mathrm{ABCG} 37$ is possibly facilitating the uptake of $\mathrm{Cs}^{+}$, which results in increased root

178 growth inhibition and leaf chlorosis (Figures 2B and 2C). If this is the case, then one would

179 expect that the loss of function mutant will show opposite response. To validate this, we used several alleles of loss-of-function mutant of ABCG37 (abcg37-2, abcg37-3, and abcg37-4).

These mutants show no visible root phenotype at control condition (Figure 2A). Unfortunately, loss-of-function mutants did not show cesium resistant phenotype.

\section{ABCG37 and ABCG33 function redundantly as cesium uptake carriers}

The unexpected wild-type like response of the loss-of-function ABCG37 mutants to cesium (Figure 2B) prompted us to hypothesize that loss of ABCG37 may be compensated by another $\mathrm{ABC}$ protein. For tonoplast localized arsenic transporter, abccl abcc 2 double mutant shows more severe phenotype compared to individual single mutants, suggesting the existence of redundant function of the ABC proteins (Song et al., 2010). To support the redundancy hypothesis, we searched the close homolog of ABCG37 based on phylogenetic analysis of 43 Arabidopsis thaliana ABCG proteins. ABCG33 turned out to be the closest homolog of ABCG37, residing in the same clade (Supplemental Figure 3A). They show $~ 80 \%$ identity at protein level (Supplemental Figure 3B).

Double knockout homozygous abcg33-1 abcg37-2 mutant was generated to test the redundant functional hypothesis. Before crossing, using gene expression analysis we confirmed that both abcg33-1 and abcg37-2 mutants are null mutants (Supplemental Figure 4). Consistent with our hypothesis, we found that abcg33-1 abcg37-2-11, abcg33-1 abcg37-2-21 and abcg33-1 abcg37-2-23 (three independent double mutant lines obtained from three independent crossing between abcg37-2 and abcg33-1) showed resistance to cesium for both root growth inhibition and leaf chlorosis (Figures 3A and 3B). The time course and dose response assay revealed that the double mutants showed strong resistance to lower concentration of $\mathrm{Cs}^{+}$-induced root growth inhibition at all incubation period (Supplemental Figures 5A and 5B). The resistant phenotype 
becomes weaker with progressively higher concentration of $\mathrm{Cs}^{+}$(Supplemental Figure 5C). However, at early incubation time point (like 2 days incubation in $\mathrm{Cs}^{+}$), the double mutants showed strong resistance to $\mathrm{Cs}^{+}$irrespective of the concentration (Supplemental Figure 5). ABCG37 has been shown to function as IBA efflux carrier (Růžička et al., 2010). Since majority of IBA functions in plant development through conversion to IAA (Růžička et al., 2010; Frick and Strader, 2017), we investigated whether abcg37, abcg33 and abcg33 abcg37 mutants show altered root growth response to exogenous IAA. All these mutants show wild-type like response to IAA-induced root growth inhibition, indicating that the altered response of these mutants to $\mathrm{Cs}^{+}$is not linked to the major endogenous form of auxin, IAA (Supplemental Figure 6). Collectively, these results confirm that ABCG33 and ABC37 act redundantly to uptake $\mathrm{Cs}^{+}$.

\section{Cesium regulates the expression of $\mathrm{ABCG37}$ and $\mathrm{ABCG} 33$ proteins at translational level}

Many of the metals $\left(\mathrm{Cd}^{2+}, \mathrm{Pb}^{2+}\right)$ regulate the gene expression of their corresponding $\mathrm{ABC}$ transporters (AtABCG36, AtABCB25, and AtABCG40) (Lee et al., 2005; Kim et al., 2006; Kim et al., 2007). Furthermore, differential expression of a group of Arabidopsis genes, including ABC proteins was observed in cesium intoxicated plants (Hampton et al., 2004). To test whether cesium regulates the expression of $A B C G 37$ and $A B C G 33$, we used quantitative real time PCR. However, compared with wild-type, we did not observe any significant changes in the transcripts of $A B C G 37$ and $A B C G 33$ in $\mathrm{Cs}^{+}$treated plants (Supplemental Figure 7). This observation is not inconsistent as in few cases it has been shown that transporters transcriptions are not affected by the application of the substrate. For instance, arsenite has no effect on expression of AtABCC1 and $A t A B C C 2$ (Song et al., 2010); rice cesium transporters are not transcriptionally altered by cesium (Yamaki et al., 2017).

The quantitative real-time PCR analyses of $A B C G 37$ and $A B C G 33$ indicated that ABCG37 and ABCG33 are not under direct transcriptional regulation of cesium. To understand whether $\mathrm{Cs}^{+}$regulates $\mathrm{ABCG} 33$ and ABCG37 at translational level, we monitored the cellular expression of these proteins using GFP tagged lines. Co-localization study with PI confirmed that both $\mathrm{ABCG} 33$ and $\mathrm{ABCG} 37$ are plasma membrane localized protein (Supplemental Figure 8). Interestingly, we found that both ABCG37-GFP and ABCG33-GFP intracellular signals are severely reduced by $1.5 \mathrm{mM}$ cesium treatment in a time dependent manner. The reduction of the GFP signal is maximum on day three but the $\mathrm{Cs}^{+}$effect on these proteins are apparent from day 2 
(Figures 4A and 4B). To clarify the specificity of $\mathrm{Cs}^{+}$effect on ABCG33 and ABCG37 proteins, we used two root specific membrane proteins, PIN2-GFP (Xu and Scheres, 2005) and EGFPLTI6b (Kurup et al., 2005). $\mathrm{Cs}^{+}$slightly reduced PIN2-GFP signal but did not affect the LTI6b expression (Figure 4B; Supplemental Figure 9). These results nullify the possibility that the $\mathrm{Cs}^{+}-$ induced inhibition of $\mathrm{ABCG} 33$ and $\mathrm{ABCG} 37$ expression is due to toxicity, rather it suggests that $\mathrm{Cs}^{+}$selectively inhibits a subset of membrane proteins.

\section{ABCG37 and ABCG33 are functionally redundant cesium influx carriers}

The physiological, molecular and cellular analyses identified ABCG33 and ABCG37 as potential $\mathrm{Cs}^{+}$influx carriers. However, evidence for direct influx activity remains lacking. The uptake activity of a protein can be assessed by either using heterologous expression system or direct in planta uptake assay. To confirm the potential role of ABCG33 and ABCG37 in $\mathrm{Cs}^{+}$ uptake, we first performed short term uptake assay in Arabidopsis roots using radio labeled cesium $\left({ }^{137} \mathrm{Cs}\right)$.

$\mathrm{Cs}^{+}$uptake capacity of wild type and double mutants was measured by direct uptake assay using radioactive ${ }^{137} \mathrm{Cs}^{+}$. The $\mathrm{Cs}^{+}$uptake was observed for $2 \mathrm{~h}$ in presence or absence of $\mathrm{K}^{+}$ at various $\mathrm{Cs}^{+}$concentrations ranging from low to high (Figure 5). The short-term assay system eliminates the possible non-specific effects on transport. Irrespective of the presence or absence of $\mathrm{K}^{+}$, abcg33-1 abcg37-2 double mutants showed a reduced cesium uptake capacity compared with wild-type at all cesium concentrations we tested (Figure 5A, 5B, 5C). To confirm that the double mutant lines truly lack the $\mathrm{Cs}^{+}$uptake capacity, we compared $\mathrm{Cs}^{+}$content in roots of the wild type and abcg33-1 abcg37-2 mutants after 3 days $\mathrm{Cs}^{+}$incubation using ICP-MS. Compared with wild type, $\mathrm{Cs}^{+}$content was significantly reduced in abcg33-1 abcg37-2 mutant lines at all $\mathrm{K}^{+}$concentration we tested (Figure 5D). The short-term uptake data along with ICP-MS data suggest that $\mathrm{ABCG} 37$ and $\mathrm{ABCG} 33$ function as cesium influx carriers.

\section{ABCG37 does not show $\mathrm{Cs}^{+}$uptake activity in Saccharomyces cerevisiae}

To evaluate $\mathrm{ABCG} 37$ activity in the $\mathrm{Cs}^{+}$uptake in a heterologous expression system, we expressed ABCG37 under GAL1 promoter in INVSc1 strain of budding yeast Saccharomyces cerevisiae. Unfortunately, no significant differences were observed for $\mathrm{Cs}^{+}$uptake between ABCG37 expressing cells and control cells at all $\mathrm{Cs}^{+}$concentrations we tested (Supplemental 
261 figure 10). These results suggest that ABCG37 needs other components to function as $\mathrm{CS}^{+}$influx 262 carrier, which is present in plant cell but absent in yeast system. This finding is not surprising as it has already been demonstrated that several plant proteins fail to transport corresponding metals when expressed in a heterologous system (Gaymard et al. 1996; Formentin et al. 2004; Ma et al. 2008), or transport with a limited capacity only after co-expressing with other proteins (Song et al. 2010; Park et al. 2012). Expression of ABCG37 in Saccharomyces cerevisiae resulted in mis localization of the protein to endoplasmic reticulum instead of plasma membrane and did not show any efflux activity for IBA (Růžička et al. 2010). When ABCG37 was expressed in Schizosaccharomyces pombe, the plasma membrane localization of ABCG37 could be achieved but the efflux activity was observed only at unusually high concentration $(250 \mu \mathrm{M})$ of IBA (Růžička et al. 2010), although ABCG37 showed IBA efflux activity at much lower concentration in planta. ABCG33 expression in Saccharomyces cerevisiae was unsuccessful.

273 Taken together, these results suggest that investigating the transporter activity of a plant protein in heterologous system is tricky and may not always mimic in planta results.

Potassium response is unaltered in abcg33abcg 37 double mutant.

Because of the structural similarity of $\mathrm{Cs}^{+}$with $\mathrm{K}^{+}$, most of the $\mathrm{Cs}^{+}$transporters found today also transport $\mathrm{K}^{+}$. Here we identified two $\mathrm{ABCG}$ proteins that modulate $\mathrm{Cs}^{+}$influx in Arabidopsis roots. To verify that these proteins solely uptake $\mathrm{Cs}^{+}$but not $\mathrm{K}^{+}$, we measured the endogenous $\mathrm{K}^{+}$content in wild-type and double mutants using ICP-MS and also compared the root growth response to a concentration of $\mathrm{K}^{+}$that inhibits $50 \%$ root growth in wild type. ICPMS data revealed no significant difference in $\mathrm{K}^{+}$content between the wild type and double mutants grown at different concentrations of $\mathrm{K}^{+}$(Figure 6A). Consistently, the double mutants respond to exogenous $\mathrm{K}^{+}$for root growth like wild-type (Figure 6B). These results provide strong evidence in support of the hypothesis that ABCG33 and ABCG37 are $\mathrm{Cs}^{+}$specific uptake carriers and act independent of $\mathrm{K}^{+}$.

\section{Discussion}

Cesium belongs to group I alkali metal with chemical properties similar to $\mathrm{K}^{+}$. Not surprisingly, the transport and translocation of $\mathrm{Cs}^{+}$in plant is tightly linked to $\mathrm{K}^{+}$. Most of the transporters that had been characterized to date as $\mathrm{Cs}^{+}$transporters are directly or indirectly linked to $\mathrm{K}^{+}$. Recently identified cesium transporters from Arabidopsis, rice, tomato and other 
system are mostly well studied potassium transporters, such as OsHAKl (Nieves - Cordones et al., 2017; Rai et al., 2017), AtKUP/HAK/KT9 (Kobayashi et al., 2010), OsHAK5, OsHAK17 (Yamaki et al., 2017), SIHAK5 (Ródenas et al., 2017). Even the ecotype screening for cesium transporters pointed out AtCNGC1 (CYCLIC-NUCLEOTIDE-GATED CHANNEL 1) as potential causal gene, which is the close homolog of AtCNGC2, a known $\mathrm{K}^{+}$transporter (Kanter et al., 2010). In another study, OsSOS 2 had been shown to transport $\mathrm{Cs}^{+}$(Ishikawa et al., 2017). However, OsSOS 2 was found to be indirectly linked to $\mathrm{K}^{+}$as in OSSOS2 mutant, $\mathrm{K}^{+}$and $\mathrm{Na}^{+}$ transporter genes (OsHAK1, OsHAK5, OsAKT1, OsHKT2;1) are downregulated at low $\mathrm{K}^{+} / \mathrm{Na}^{+}$ (Ishikawa et al., 2017). It is predicted that $\mathrm{Cs}^{+}$uptake is reduced due to the lower expression of these transporters in presence of the $\mathrm{K}^{+} / \mathrm{Na}^{+}$imbalance (Ishikawa et al., 2017). Altogether, these results suggest a possible single pathway of $\mathrm{Cs}^{+}$transport in plants. However, this idea is partially correct as all the recently identified low cesium concentration mutants function only under low $\mathrm{K}^{+}$content (Qi et al., 2008; Nieves-Cordones et al., 2017, Ishikawa et al., 2017; Rai et al. 2017). At higher $\mathrm{K}^{+}$concentrations, the selectivity for $\mathrm{K}^{+}$strongly increases and this selective discrimination indicates the existence of alternate route of $\mathrm{Cs}^{+}$transport in planta.

In the present study, we identified two $\mathrm{ABC}$ proteins (ABCG33 and $\mathrm{ABCG} 37$ ) that function as cesium influx carriers. The broader specificity of $\mathrm{ABC}$ proteins make them excellent transporter of many metals, hormones and chemical compounds. Previously, ABCG37 has been reported to act as efflux carrier of IBA (Růžička et al., 2010). Here we demonstrated that ABCG37 and ABCG33 function as cesium influx carriers. This observation is not inconsistent as the same $\mathrm{ABC}$ transporter can transport various substrates. For instance, ABCC1 and ABCC2 transport arsenic, mercury, and cadmium (Lee et al., 2005; Kim et al., 2006; Kim et al., 2007; Song et al., 2010; Park et al., 2012). AtPDR8/ABCG36 transports cadmium, lead and IBA (Kim et al., 2007, Růžička et al., 2010). AtPDR12/ABCG40 transports both cadmium and ABA (Lee et al., 2005; Kang et al., 2010) Similarly, ABCG37 also shows a wide substrate specificity and transports IBA, 2,4-D and coumarin (Ito and Gray, 2006; Růžička et al., 2010; Fourcroy et al., 2014). These substrates are not even distantly related to each other structurally. In contrast, the functional role of ABCG33 is yet undefined although it may function in transporting monolignol (Schuetz et al., 2014). The findings that ABCG37 can function as both influx (for $\mathrm{Cs}^{+}$) or efflux (for 2,4-D and IBA) is not inconsistent as based on the substrate, ABC transporters may act as influx, efflux or both at the same time. PGP4/ABCB4 was demonstrated as influx (Terasaka et 
al., 2005), efflux (Cho et al., 2007) and both influx/efflux (Yang and Murphy, 2009; Kubeš et al., 2012; Swarup and Péret, 2012) carriers of auxin. Similarly, PDR12/ABCG40 has been shown to function as efflux carrier for cadmium but as influx carrier for ABA (Lee et al., 2005; Kang et al., 2010)

Since ABCG37 has been shown to be linked to transport 2,4-D and IBA (Ito \& Gray, 2006; Růžička et al., 2010), it may be hypothesized that the $\mathrm{Cs}^{+}$-induced inhibition of root growth is linked to auxin. Several lines of evidence argue against this notion; 1) The phenotype of $\mathrm{Cs}^{+}$-induced inhibition of plant growth is completely different than the auxin-induced inhibition. Long term $\mathrm{Cs}^{+}$treatment results in leaf chlorosis, which is never induced by auxin treatment (Figures 1,2,3). Additionally, the double mutant abcg33-1abcg37-2 shows strong resistance to $\mathrm{Cs}^{+}$-induced leaf chlorosis (Figure 3). 2) Auxin-induced root growth inhibition is associated with an increase in lateral root number. In case of $\mathrm{Cs}^{+}$-induced inhibition, the lateral root development is suppressed (Figures 1,2,3), indicating that these two chemicals use distinct pathways to inhibit the root growth. 3) All the single or double mutants of ABCG33 and ABCG37 show wild-type like root elongation response to major endogenous auxin IAA (Supplemental Figure 6). Previously it was demonstrated that ABCG37 mutants show wild-type like respons to IAA (Ito \& Gray, 2006; Růžička et al., 2010), which is consistent with our results. Further, 2,4-D is not an endogenous auxin and hence $\mathrm{Cs}^{+}$-induced inhibition is not linked to 2,4-D. In case of IBA, it is believed that majority of IBA functions in plant development through conversion to IAA (Růžička et al., 2010; Frick and Strader, 2017). Since all the ABCG33 and ABCG37 single and double mutants respond to IAA like wild-type, it is reasonable to speculate that the response of these mutants to $\mathrm{Cs}^{+}$is independent of auxin.

Our physiological, genetic, cell biological and direct transport assay data indicated that ABCG33 and ABCG37 function redundantly in uptaking $\mathrm{Cs}^{+}$. Additionally, the reduction in $\mathrm{Cs}^{+}$ uptake in abcg33 abcg37 double mutant is independent of $\mathrm{K}^{+}$availability in the media as similar reduction in $\mathrm{Cs}^{+}$uptake was observed in presence or absence of $\mathrm{K}^{+}$(Figure 5). The specificity of these proteins to uptake only $\mathrm{Cs}^{+}$but not $\mathrm{K}^{+}$was also confirmed by measuring $\mathrm{K}^{+}$concentration and root growth response to exogenous $\mathrm{K}^{+}$in the double mutant lines (Figure 6). Unfortunately, ABCG37 did not show any $\mathrm{Cs}^{+}$influx activity in heterologous system. This is not inconsistent as the expression of plant proteins in heterologous system widely varies depending on the system 
that is used, and in many cases plant proteins do not express in heterologous system. For instance, AKT1 and DKT1 showed disturbed cell membrane electrical stability and inactivity when expressed in oocyte system (Gaymard et al., 1996; Formentin et al., 2004). Dreyer et al. also elegantly showed the problems with the heterologous expression system in expressing plant potassium transporters highlighting the differences between the expression systems (Dreyer et al., 1999). Lsi2, which functions as arsenite and silicon transporter in planta, did not show any transport activity when it was expressed using heterologous systems (Ma et al., 2008). Bernaudat et al. performed extensive analyses of expression of plant membrane proteins in wide range of heterologous expression systems and clearly showed that the expression varies depending on the expression system and in some cases the plant proteins simply do not express in heterologous system. The authors concluded that "with heterologous protein expression, the recombinant produced does not always truly resemble the native protein. Conditions that produce the largest amount of protein do not necessarily generate functional proteins" (Bernaudat et al., 2011). This conclusion was also supported by several published work for mammalian transporter proteins (Lenoir et al., 2002; Griffith et al., 2003; Tate et al., 2003; Bonander et al., 2005; Midgett and Madden, 2007). Additionally, since the activity of the transporters in plants may be modulated by their interactions with other proteins, the inability of the transporters to transport their respective substrates when expressed in heterologous system is not unusual as the interacting proteins that are required for proper functioning may be missing in heterologous expression systems (Zourelidou et al., 2014). Consistently, ABCC1 and ABCC2 could transport arsenic only when they were expressed in phytochelatins (PCS) producing yeast strain (Song et al., 2010). Similar results were observed for mercury. ABCC1 and ABCC2 transported more mercury when

374 it was expressed in PCS producing yeast compared with yeast strain that does not produce any 375 PCS (Park et al., 2012). Interestingly, the same ABCC1 and ABCC2 failed to transport any cadmium even when they were expressed in PCS producing yeast strain, although they could 377 transport cadmium in planta (Perk et al., 2012). Hence, the inability of the plant transport proteins to transport substrate when expressed in heterologous system does not exclude them to function as transporters in planta.

Previously, plasma membrane-localized metal transporters were established based on content through ICP-MS. For instance, AtPDR8/ABCG36 and AtATM3/ABCG25 were 
383

384

385

386

387

388

389

390

391

392

393

394

395

396

397

398

399

400

401

402

403

404

405

406

407

408

409

410

411

identified as $\mathrm{Cd}$ transporter based on radioactive ${ }^{109} \mathrm{Cd}$ transport assay and ICP-MS (Kim et al., 2006; Kim et al., 2007). Additionally, AtPDR12/ABCG40 was identified as Cd transporter based on ICP-MS analysis, where increased or decreased content of Cd was observed for atpdr12-1 and overexpression line of AptPDR12, respectively (Lee et al., 2005). These results along with the observed in planta $\mathrm{Cs}^{+}$influx activity of $\mathrm{ABCG} 33$ and $\mathrm{ABC} 37$ characterized these two $\mathrm{ABC}$ proteins as potential candidates for Arabidopsis specific $\mathrm{Cs}^{+}$influx carriers.

Our finding that $\mathrm{ABC}$ proteins may function as $\mathrm{Cs}^{+}$specific influx carriers is supported by the recent identification of cesium transporters from the screening of rice-transporter-enriched yeast expression library where rice OsABCG45 has been shown to be a functionally active cesium transporter in yeast (Yamaki et al., 2017). OsABCG45 shows $~ 50 \%$ homology with both ABCG33 and ABCG37 from Arabidopsis. $\mathrm{Cs}^{+}$intoxification results in upregulation of AtABCG16, AtABCA7 and AtNAP5 in Arabidopsis (Hampton et al., 2004). In addition, during our screening, we found additional three loss of function ABC mutants; abcb15, abcg36 and abcg42 showing hypersensitive response to $\mathrm{Cs}^{+}$-induced inhibition of root growth. Collectively, these results suggest that beside $\mathrm{ABCG} 33$ and $\mathrm{ABCG} 37$, other $\mathrm{ABC}$ transporters may function as cesium transporters.

Another possibility remains open that the reduced uptake or accumulation of $\mathrm{Cs}^{+}$in the abcg33abcg37 double mutant may be due to nonspecific effect of the mutations to other $\mathrm{K}^{+}$ transporters. Although we do not completely rule out the possibility, several lines of experimental evidence go against this possibility. Measurement of $\mathrm{K}^{+}$content in the double mutant in presence of low to high concentrations of $\mathrm{K}^{+}$did not reveal any alteration in the potassium accumulation in the double mutant compared with the wild-type (Figure 6A). The potassium content was measured after 3-day treatment confirming that there are no non-specific changes in other transport proteins that may involve in transporting $\mathrm{K}^{+}$. Further, the root growth response of double mutant under $\mathrm{K}^{+}$showed no changes in the root elongation response suggesting that these mutations do not alter potassium response (Figure 6B). Measurement of $\mathrm{Cs}^{+}$content in presence of variable concentrations of $\mathrm{K}^{+}$revealed a similar trend of decreasing $\mathrm{Cs}^{+}$content under high $\mathrm{K}^{+}$condition both in wild type and double mutant (Figure 5D). If there was a change in $\mathrm{K}^{+}$transport in double mutant, one would expect to observe a clear difference in 
412 double mutant. Based on these multiple lines of evidence, we concluded that the double mutant

413 has an unaltered $\mathrm{K}^{+}$transport.

Although it has been shown that both low and high $\mathrm{Cs}^{+}$can alter the gene expression in Arabidopsis (Hampton et al., 2004; Sahr et al., 2005a, Sahr et al., 2005b), ABCG33 and ABCG37 are not under the transcriptional regulation of $\mathrm{Cs}^{+}$. Cesium alters the expression of ABCG33 and ABCG37 protein in a time dependent manner. Since ABCG33 and ABCG37 function as potential $\mathrm{Cs}^{+}$influx carriers, one plausible explanation is plants shut off the transporters to protect it from long term toxicity. This process is possibly regulated by the cesium-mediated post-translational regulation of transporters. However, the mechanism of this regulation is still unclear. Similar observation was reported for BRASSINOSTEROID INSENSITIVE 1(BRI1) receptor regulation at prolonged ambient temperature. Although $26^{\circ} \mathrm{C}$ incubation did not alter the transcript of $B R I 1$, the protein expression was shown to be decreased

424 in a time dependent manner (Martins et al., 2017). Polyubiquitin-dependent endocytosis and 425 degradation have been suggested to regulate this process (Martins et al., 2017). Cesium toxicity 426 has already been reported to induce proteolytic degradation of AGO1 possibly through 427 autophagy (Jung et al., 2015). The ferrous Fe uptake transporter IRON-REGULATED 428 TRANSPORTER1 (IRT1) is shown to be rapidly and constitutively degraded through a ring E3 ubiquitin ligase IRT Degradation Factor 1 (IDF1)-mediated pathway to maintain cellular Fe 430 homeostasis (Shin et al., 2013). IRT1 also serves as a transceptor, directly sensing non-iron metals using a histidine-stretch in IRT1, and regulates its own degradation by differential 432 ubiquitination upon metal stress to maximize iron uptake while limiting the absorption of highly reactive and potentially toxic non-iron metals. (Dubeaux et al, 2018). Recent studies on ethylene 434 signaling provided further insight about translational regulation. C-terminal end of EIN2 (EIN2435 CEND) interacts with 3'UTR of EBF1/2 and represses the translation of EBF1/2 by directing 436 them towards P body for RNA decay. As a result, EBF1/2 become unable to degrade EIN3/EIL1, 437 major transcription factors for ethylene response (Li et al., 2015; Merchante et al., 2015). These results indicate the existence of various mechanisms for post translational regulation of proteins. 439 Future research focusing on understanding the cesium mediated translational regulation will shed 440 light on intracellular $\mathrm{Cs}^{+}$signaling events. 
The present work identified the long-sought $\mathrm{K}^{+}$independent uptake carriers of $\mathrm{Cs}^{+}$. ABCG protein mediated $\mathrm{Cs}^{+}$uptake facilitates the $\mathrm{Cs}^{+}$transport along with known $\mathrm{K}^{+}$ transporters. Based on the results, we developed a working model where cesium uptake and transport inside the cell are mediated by potassium transporters, ABC transporters (ABCG37 and ABCG33) and other unknown transporters (Figure 7). Hence, in the double knockout mutant we did not observe complete resistance to cesium. Bioremediation of the contaminated soil is a clever and affordable technology, which is largely unused for $\mathrm{Cs}^{+}$removal because of the similarity in chemical properties of $\mathrm{Cs}^{+}$to $\mathrm{K}^{+}$, a major macronutrient for plant growth. Removal of $\mathrm{K}^{+}$transporters affects the plant growth and also low $\mathrm{K}^{+}$content soil is also a common requirement to transport contaminated $\mathrm{Cs}^{+}$(Nieves - Cordones et al., 2017; Rai et al., 2017; Ródenas et al., 2017; Yamaki et al., 2017). Future research aiming in generating new transgenic plants manipulating both $\mathrm{K}^{+}$transport pathway and the newly identified $\mathrm{ABC}$ protein mediated $\mathrm{Cs}^{+}$transport pathway will facilitate the efficient removal of $\mathrm{Cs}^{+}$from the contaminated soil.

\section{Methods}

\section{Plant materials}

All lines are in the Columbia background of Arabidopsis thaliana. abcbl/mdrl, $a b c b 2 / m d r 2, a b c b 3 / m d r 3, a b c b 4 / m d r 4, a b c b 5 / m d r 5, a b c b 6 / m d r 5, a b c b 6 / m d r 6, a b c b 7 / m d r 7$, abcb9/mdr9, abcb10/mdr10, abcb11/mdr8, abcb12/mdr16, abcb13/mdr15, abcb14/mdr12, abcb15/mdr13, abcb16/mdr18, abcb17/mdr19, abcb18/mdr20, abcb19/mdr11, abcb20/mdr14, $a b c b 22 / m d r 21$ were provided by Edgar Spalding, Department of Botany, University of Wisconsin-Madison and abcg37-1/pdr9-1 was provided by Willian M. Gray, Department of Plant Biology, University of Minnesota. Other T-DNA insertion mutants were obtained from ABRC (Arabidopsis Biological Resource Center), and listed in the Supplemental Table 2.

ABCG37-GFP (Růžička et al., 2010), ABCG33-GFP (Schuetz et al., 2014), PIN2-GFP (Xu and Scheres, 2005), EGFP-LTI6b (Kurup et al., 2005) and pCyclinB1;1-GUS were described elsewhere (Colón - Carmona et al., 1999).

Three independent double knockout mutants (abgc37-2 abcg33-1) were generated by genotyping are listed in the Supplemental Table 1. 


\section{Growth conditions}

Surface-sterilized seeds were placed in round, 9-cm Petri plates on modified Hoagland medium (Baskin and Wilson, 1997) containing 1\% (w/v) Sucrose and 0.8\% (w/v) agar (Difco Bacto agar; BD Laboratories, http://www.bd.com). Two days after stratification at $4^{0} \mathrm{C}$ in the dark, plates were transferred to a growth chamber (NK System; LH-70CCFL-CT, http://www.nihonika.co.jp) at $23^{0} \mathrm{C}$ under continuous white light (at an irradiance of $\sim 100 \mu \mathrm{mol}$ $\mathrm{m}^{-2} \mathrm{~s}^{-1}$ ). The seedlings were grown vertically for 3 days. For cesium chloride treatment, 3-daysold seedlings were transferred to cesium chloride containing plates of various concentrations and incubate for various time points. Root elongation data represent the root elongation after transferring to the corresponding media and mentioned concentrations. To measure the root elongation, photographs of plates were taken using a digital camera (Power Shot A640, Canon, http://canon.jp) and analyzed by an image analyzing software ImageJ (http://rsb.info.nih.gov/ij/).

For auxin response assay, 4-d-old light grown Col-0, abcg37-1, abcg37-2, acbg33-1 and abcg37-2 abcg33-1 seedlings were transferred to DMSO, 15nM and 30nM IAA containing plates and kept at $23^{\circ} \mathrm{C}$ under yellow light for three days. After the incubation, root elongation was measured as described above.

\section{Chemicals}

Cesium chloride was purchased from Sigma Chemicals (www.sigmaaldrich.com). Propidium idodide was purchased from Invitrogen (www.thermofisher.com) . The carrier-free ${ }^{137} \mathrm{Cs}$ solution (3.7MBq $\mathrm{mL}^{-1}$ ) was purchased from Eckert \& Ziegler (https://www.ezag.com). Other chemicals were purchased from Wako, Japan (www.wako-chem.co.jp).

\section{Kinematic analysis}

Kinematic analysis was performed as described earlier (Rahman et al., 2007). In brief, seedlings were grown vertically for 4 days after stratification. On day 4 , seedlings were transferred to plates supplemented with or without and $1.5 \mathrm{mM}$ cesium chloride and grown vertically for another 3 days. Root elongation was measured by scoring the position of the root tip on the back of the Petri plate once per day. After the end of the incubation, cortical cell length was measured using light microscope (Nikon Diaphot) equipped with a digital camera control unit (Digital Sight [DS-L2]; Nikon, Japan, https://www.nikon.co.jp). To ensure newly matured 
cells were scored, cells were measured for the root zone, where root hair length was roughly half maximal. The length of 10 mature cortical cells was measured from each root, with 8 roots used per treatment. The cell production rate was calculated by taking the ratio of root elongation rate and average cell length and average cell length for each individual and averaging over all roots in the treatment. The data were obtained from at least three independent biological replicates.

\section{GUS staining}

GUS staining was performed as described earlier (Okamoto et al., 2008). In brief, 3-d-old seedlings were transferred to $1.5 \mathrm{mM}$ cesium chloride containing agar plate and grown vertically at $23^{\circ} \mathrm{C}$ under continuous white light. After three days incubation, seedlings were transferred to GUS staining buffer (100 mM sodium phosphate, $\mathrm{pH} 7.0,10 \mathrm{mM}$ EDTA, 0.5mM potassium ferricyanide, $0.5 \mathrm{mM}$ potassium ferrocyanide, and $0.1 \%$ Triton X-100) containing $1 \mathrm{mM} \mathrm{X-gluc}$ and incubated at $37^{\circ} \mathrm{C}$ in the dark for $3 \mathrm{~h}$. The roots were imaged with a light microscope (Nikon Diaphot) equipped with a digital camera control unit (Digital Sight [DS-L2]; Nikon, Japan).

\section{Propidium Iodide staining}

$0.01 \mathrm{mg} / \mathrm{ml}$ Propidium Iodide (PI) solution was used to stain the root and subjected to confocal microscope imaging immediately. Roots were mounted in PI solution containing coverslip and imaged using a Nikon laser scanning microscope (Eclipse Ti equipped with Nikon C2 Si laser scanning unit, https://www.nikon.co.jp) with a X20 objective. The imaging was performed within 5 minutes from the start of the PI staining. The experiment was repeated three times.

\section{Gene expression analysis}

3-d-old vertically grown Arabidopsis thaliana seedlings were transferred to $1.5 \mathrm{mM}$ cesium chloride containing agar plate and incubated at $23^{\circ} \mathrm{C}$ for additional three days. After the treatment, RNA was extracted from the root tissue using RNA Extraction Kit (APRO Science, Japan, www.aprosci.com) with on-column DNA digestion to remove residual genomic DNA using RNase-free DNase according to manufacturer's protocol. Extracted RNA was tested for quality and quantity. Each RNA concentration was normalized with RNase free water. $500 \mathrm{ng}$ RNA was used to synthesize cDNA using Rever Tra Ace qPCR RT master mix (Toyobo, Japan, www.toyobo-global.com). Quantitative PCR reactions were performed using the Takara TP-850 
528 thermal cycler (Takara Bio, Japan, www.takara-bio.com) and SsoAdvanced ${ }^{\mathrm{TM}}$ Universal SYBR $^{\circledR}$

529 Green Supermix (BIO-RAD, USA, www.bio-rad.com). The reaction was performed as per 530 manufacturer's instruction. For quantification of $A B C G$ expression, we used the $2-^{\Delta \Lambda} \mathrm{CT}$ (cycle 531 threshold) method with a normalization to the ef1 $\alpha$ expression (Hanzawa et al., 2013). Data were 532 obtained from three biological replicates. Primers used for the gene expression analysis are listed 533 in Supplemental Table 1.

For RT-PCR analysis (Supplemental Figure 4), RNA was extracted from 7-day-old vertically grown seedlings and cDNA was prepared as described above. RT-PCR was performed 536 using GoTaq ${ }^{\circledR}$ DNA polymerase (Promega, https://www.promega.com) and corresponding 537 primers for 28 cycles. Primers used for the gene expression analysis are listed in the 538 Supplemental Table 1.

539

540

541

542

543

544

545

546

547

548

549

550

551

552

553

554

555

\section{Live-Cell imaging}

To image GFP, the 3-day-old seedlings were transferred to $1.5 \mathrm{mM}$ cesium chloride containing plates and incubated at $23^{\circ} \mathrm{C}$ under continuous light for three days. Images were taken in every $24 \mathrm{~h}$ time interval up to $72 \mathrm{~h}$ (Figures $4 \mathrm{~A}$ and $4 \mathrm{~B}$; Supplemental Figure 8). For colocalization study, five-day-old ABCG37 and ABCG33-GFP seedlings were grown and stained with $0.01 \mathrm{mg} / \mathrm{ml}$ propidium iodide (Supplemental Figure 8). After mounting on a large cover glass, the roots were imaged using a Nikon laser scanning microscope (Eclipse Ti equipped with Nikon C2 Si laser scanning unit) with a X20 objective. Same confocal settings were used for each group of experiments. Fluorescence intensities were measured by drawing same region of interest (ROI) in the images obtained from live-cell imaging using Image $\mathbf{J}$ software.

\section{Cesium transport assay}

4-day-old light grown seedlings were incubated in $0.1 \mu \mathrm{M}, 10 \mu \mathrm{M}, 1.5 \mathrm{mM}$ and $15 \mathrm{mM}$ ${ }^{137} \mathrm{Cs}^{+}$containing liquid Hoagland solution for $2 \mathrm{~h}$ both in presence $(6 \mathrm{mM} \mathrm{K})$ or absence of potassium, transferred over Nylon mesh and briefly washed with liquid Hoagland solution three times. $10 \mathrm{~mm}$ root tip from 10 seedlings were collected for each sample and placed into the scintillation vial with 500 $\mu \mathrm{L}$ MicroScint 40 (Perkin Elmer, Inc., USA, www.perkinelmer.com). 
556 The uptake of ${ }^{137} \mathrm{Cs}^{+}$was determined with a NaI scintillation counter (ARC-300, Aloka, Japan,

557 www.hitachi-aloka.co.jp). The experiment was repeated for three times.

558

559

560

561

562

563

564

565

566

567

568

569

570

571

572

573

574

575

576

577

578

579

580

581

582

583

\section{Measurements of ion contents}

Three-day-old Col-0and double knockout mutant seedlings were transferred to control and $1.5 \mathrm{mM}$ cesium chloride containing plates with variable $\mathrm{K}^{+}$concentrations, and incubated for three days at $23^{0} \mathrm{C}$ under continuous white light. Whole seedlings were collected, washed three times with ultrapure water, soaked in the paper towel and the fresh weight was measured. Samples were dried at $65^{\circ} \mathrm{C}$ and digested using ultrapure nitric acid (Kanto Chemical, Japan, https://www.kanto.co.jp) at $95^{\circ} \mathrm{C}$ for $600 \mathrm{~min}$. Ion contents were determined using an inductive coupled plasma mass spectrometer (ICP-MS, NexION 350S, Perkin Elmer, Japan).

\section{Cesium transport assay in Saccharomyces cerevisiae}

To evaluate the $\mathrm{Cs}^{+}$transport by $\mathrm{ABCG} 37$, we performed the yeast culture experiment under various $\mathrm{Cs}^{+}$concentrations. The ABCG37 cDNA was cloned into the pENTR/D-TOPO vector (Invitrogen, USA). Primers (ABCG37_F, ABCG37_R) used for cloning are listed in the Supplementary table 1. Subsequently, ABCG37 cDNA was transferred into the destination vector pYES-DEST52 (Invitrogen, USA) to construct the expression vector for yeast transformation. The yeast strain, INVSc1 (MATa his3D1 leu2 trp1-289 ura3-52 MAT his3D1 leu2 trp1-289 ura3-52), was transformed with the pYES-DEST52-ABCG37. After confirming the growth in the overnight culture with $2 \%$, SC-URA medium, the yeast strains were washed with RO water twice, then cultured in SC-URA medium with $2 \%$ galactose in $0.1 \mu \mathrm{M}, 100 \mu \mathrm{M}$ and $1.5 \mathrm{mM}$ of $\mathrm{Cs}^{+}$. After 24 hours, OD600 of each sample was measured to adjust equal number of cells for each treatment. The collected samples were washed with RO water twice and digested by $13 \mathrm{~N}$ nitric acid. $\mathrm{Cs}^{+}$content in the sample solution was measured by inductively coupled plasma mass spectrometry ICP-MS (NexION 350S, PerkinElmer).

\section{Bioinformatics analysis}

Mutational information of ABCG37 mutants were collected from SALK T-DNA repository (http://signal.salk.edu/cgi-bin/tdnaexpress) and schematic diagram of mutants were drawn based on Exon-Intron Graphic maker (http://wormweb.org/exonintron). 
Protein sequences of ABCG transporters were collected from TAIR database

585

586

587

588

589

590

591

592

593

594

595

596

597

598

599

600

601

602

603

604

605

606

607

608

609

610

611

\section{Acknowledgements}

The authors thank Edgar Spalding (Department of Botany, University of Wisconsin Madison), William M. Gray (college of biological sciences, University of Minnesota), Angus Murphy (University of Maryland, USA), Lacey Samuels (University of British Columbia, Canada), and Ben Scheres (University of Utrecht, The Netherlands) for sharing materials. This work was partially funded by Iwate University President Fund (A.R.), UGAS, IU Research fund 2017 (M.A.A.), and Japan Science and Technology Agency (JST) [PRESTO \# 15665950] (K. T.). M.A.A. was supported by MEXT fellowship.

\section{Author Contribution}

A.R. designed and supervised the experiments. Initial screening of $\mathrm{ABCB}$ and $\mathrm{ABCG}$ mutants was done by S.K. M.A.A. and K.I. performed the experiments. R.S. and K.T. assisted for the $\mathrm{Cs}^{+}$uptake assay, ICP-MS experiment and data analysis. A.R. and M.A.A. and K.T. analyzed the data. A.R. and M.A.A. wrote the manuscript.

\section{References}

Baskin, T.I., and Wilson, J.E. (1997). Inhibitors of protein kinases and phosphatases alter root morphology and disorganize cortical microtubules. Plant Physiol. 113, 493-502.

Bernaudat, F., Frelet-Barrand, A., Pochon, N., Dementin, S., Hivin, P., Boutigny, S., Rioux, J.-B., Salvi, D., Seigneurin-Berny, D., and Richaud, P. (2011). Heterologous expression of membrane proteins: choosing the appropriate host. PloS one 6, e29191.

Bonander, N., Hedfalk, K., Larsson, C., Mostad, P., Chang, C., Gustafsson, L., and Bill, R.M. (2005). Design of improved membrane protein production experiments: quantitation of the host response. Protein Sci. 14, 1729-1740.

Cho, M., Lee, S.H., and Cho, H.-T. (2007). P-Glycoprotein4 displays auxin efflux transporterlike action in Arabidopsis root hair cells and tobacco cells. The Plant Cell 19, 3930-3943. Collander, R. (1941). Selective absorption of cations by higher plants. Plant Physiol. 16, 691. 
Colón-Carmona, A., You, R., Haimovitch-Gal, T., and Doerner, P. (1999). Spatio-temporal analysis of mitotic activity with a labile cyclin-GUS fusion protein. Plant J. 20, 503-508.

Cooghtrey, P., Jackson, D., and Thorne, M. (1983). Radionuclide distribution and transport in terrestrial and aquatic ecosystems: A critical review of data: CRC press.

Dreyer, I., Horeau, C., Lemaillet, G., Zimmermann, S., Bush, D.R., Rodríguez-Navarro, A., Schachtman, D.P., Spalding, E.P., Sentenac, H., and Gaber, R.F. (1999). Identification and characterization of plant transporters using heterologous expression systems. J. Exp. Bot. 50,1073-1087.

Dubeaux, G., Neveu, J., Zelazny, E., and Vert, G. (2018). Metal sensing by the IRT1 transporter-receptor orchestrates its own degradation and plant metal nutrition. Mol.Cell. 69, 953-964.

Formentin, E., Varotto, S., Costa, A., Downey, P., Bregante, M., Naso, A., Picco, C., Gambale, F., and Lo Schiavo, F. (2004). DKT1, a novel K+ channel from carrot, forms functional heteromeric channels with KDC1. FEBS Lett. 573, 61-67.

Fourcroy, P., Sisó-Terraza, P., Sudre, D., Savirón, M., Reyt, G., Gaymard, F., Abadía, A., Abadia, J., Álvarez-Fernández, A., and Briat, J.F. (2014). Involvement of the ABCG37 transporter in secretion of scopoletin and derivatives by Arabidopsis roots in response to iron deficiency. New Phytol. 201, 155-167.

Fujiwara, T. (2013). Cesium uptake in rice: possible transporter, distribution, and variation. In Agricultural Implications of the Fukushima Nuclear Accident (Springer), pp. 29-35.

Gaymard, F., Cerutti, M., Horeau, C., Lemaillet, G., Urbach, S., Ravallec, M., Devauchelle, G., Sentenac, H., and Thibaud, J.-B. (1996). The Baculovirus/Insect Cell System as an Alternative to Xenopus Oocytes first characterization of the AKT1 K+ channel from Arabidopsis thaliana. J. Biol. Chem. 271, 22863-22870.

Griffith, D.A., Delipala, C., Leadsham, J., Jarvis, S.M., and Oesterhelt, D. (2003). A novel yeast expression system for the overproduction of quality-controlled membrane proteins. FEBS Lett. 553, 45-50.

Hampton, C.R., Bowen, H.C., Broadley, M.R., Hammond, J.P., Mead, A., Payne, K.A., Pritchard, J., and White, P.J. (2004). Cesium toxicity in Arabidopsis. Plant Physiol. 136, 3824-3837. 
Hanzawa, T., Shibasaki, K., Numata, T., Kawamura, Y., Gaude, T., and Rahman, A. (2013). Cellular auxin homeostasis under high temperature is regulated through a SORTING NEXIN1-dependent endosomal trafficking pathway. Plant Cell 25, 3424-3433.

Isaure, M.-P., Fraysse, A., Deves, G., Le Lay, P., Fayard, B., Susini, J., Bourguignon, J., and Ortega, R. (2006). Micro-chemical imaging of cesium distribution in Arabidopsis thaliana plant and its interaction with potassium and essential trace elements. Biochimie 88, 1583-1590.

Ishikawa, S., Hayashi, S., Abe, T., Igura, M., Kuramata, M., Tanikawa, H., Iino, M., Saito, T., Ono, Y., and Ishikawa, T. (2017). Low-cesium rice: mutation in OsSOS2 reduces radiocesium in rice grains. Sci Rep 7, 2432.

Ito, H., and Gray, W.M. (2006). A gain-of-function mutation in the Arabidopsis pleiotropic drug resistance transporter PDR9 confers resistance to auxinic herbicides. Plant Physiol. 142, 63-74.

Jung, I.L., Ryu, M., Cho, S.K., Shah, P., Lee, J.H., Bae, H., Kim, I.G., and Yang, S.W . (2015). Cesium toxicity alters MicroRNA processing and AGO1 expressions in Arabidopsis thaliana. PloS one 10, e0125514.

Kang, J., Hwang, J-U., Lee, M., Kim, Y-Y., Assmann, S.M., Martinoia, E., and Lee, Y. (2010). PDR-type ABC transporter mediates cellular uptake of the phytohormone abscisic acid. Proc. Natl. Acad. Sci. USA 107, 2355-2360.

Kanter, U., Hauser, A., Michalke, B., Dräxl, S., and Schäffner, A.R. (2010). Caesium and strontium accumulation in shoots of Arabidopsis thaliana: genetic and physiological aspects. J. Exp. Bot. 61, 3995-4009.

Kim, D.-Y., Bovet, L., Kushnir, S., Noh, E.W., Martinoia, E., and Lee, Y. (2006). AtATM3 is involved in heavy metal resistance in Arabidopsis. Plant Physiol. 140, 922-932.

Kim, D.Y., Bovet, L., Maeshima, M., Martinoia, E., and Lee, Y. (2007). The ABC transporter AtPDR8 is a cadmium extrusion pump conferring heavy metal resistance. Plant J. 50, 207-218.

Kobayashi, D., Uozumi, N., HISAMATSU, S.i., and Yamagami, M. (2010). AtKUP/HAK/KT9, a K+ transporter from Arabidopsis thaliana, mediates Cs+ uptake in Escherichia coli. Biosci., Biotechnol., Biochem. 74, 203-205. 
Kubeš, M., Yang, H., Richter, G.L., Cheng, Y., Młodzińska, E., Wang, X., Blakeslee, J.J., Carraro, N., Petrášek, J., and Zažímalová, E. (2012). The Arabidopsis concentrationdependent influx/efflux transporter ABCB4 regulates cellular auxin levels in the root epidermis. Plant J. 69, 640-654.

Kurup, S., Runions, J., Köhler, U., Laplaze, L., Hodge, S., and Haseloff, J. (2005). Marking cell lineages in living tissues. Plant J. 42, 444-453.

Lee, M., Lee, K., Lee, J., Noh, E.W., and Lee, Y. (2005). AtPDR12 contributes to lead resistance in Arabidopsis. Plant Physiol. 138, 827-836.

Lenoir, G., Menguy, T., Corre, F., Montigny, C., Pedersen, P.A., Thinès, D., le Maire, M., and Falson, P. (2002). Overproduction in yeast and rapid and efficient purification of the rabbit SERCA1a Ca 2+-ATPase. Biochim. Biophys. Acta Biomembranes 1560, 67-83.

Li, W., Ma, M., Feng, Y., Li, H., Wang, Y., Ma, Y., Li, M., An, F., and Guo, H. (2015). EIN2-directed translational regulation of ethylene signaling in Arabidopsis. Cell 163, 670-683.

Ma, J.F., Yamaji, N., Mitani, N., Xu, X.-Y., Su, Y.-H., McGrath, S.P., and Zhao, F.-J. (2008). Transporters of arsenite in rice and their role in arsenic accumulation in rice grain. Proc. Natl. Acad. Sci. USA 105, 9931-9935.

Merchante, C., Brumos, J., Yun, J., Hu, Q., Spencer, K.R., Enríquez, P., Binder, B.M., Heber, S., Stepanova, A.N., and Alonso, J.M. (2015). Gene-specific translation regulation mediated by the hormone-signaling molecule EIN2. Cell 163, 684-697.

Midgett, C.R., and Madden, D.R. (2007). Breaking the bottleneck: eukaryotic membrane protein expression for high-resolution structural studies. J. Struct. Biol. 160, 265-274.

Nieves-Cordones, M., Mohamed, S., Tanoi, K., Kobayashi, N.I., Takagi, K., Vernet, A., Guiderdoni, E., Périn, C., Sentenac, H., and Véry, A.A. (2017). Production of low$\mathrm{Cs}+$ rice plants by inactivation of the $\mathrm{K}+$ transporter OsHAK1 with the CRISPR-Cas system. Plant J. 92: 43-56.

Okamoto, T., Tsurumi, S., Shibasaki, K., Obana, Y., Takaji, H., Oono, Y., and Rahman, A. (2008). Genetic dissection of hormonal responses in the roots of Arabidopsis grown under continuous mechanical impedance. Plant Physiol. 146, 1651-1662. 
Park, J., Song, W.Y., Ko, D., Eom, Y., Hansen, T.H., Schiller, M., Lee, T.G., Martinoia, E., and Lee, Y. (2012). The phytochelatin transporters AtABCC1 and AtABCC2 mediate tolerance to cadmium and mercury. Plant J. 69, 278-288.

Rahman, A., Bannigan, A., Sulaman, W., Pechter, P., Blancaflor, E.B., and Baskin, T.I. (2007). Auxin, actin and growth of the Arabidopsis thaliana primary root. Plant J. 50, 514-528.

Rai, H., Yokoyama, S., Satoh-Nagasawa, N., Furukawa, J., Nomi, T., Ito, Y., Fujimura, S., Takahashi, H., Suzuki, R., and Yousra, E. (2017). Cesium Uptake by Rice Roots Largely Depends Upon a Single Gene, HAK1, Which Encodes a Potassium Transporter. Plant Cell Physiol. 58, 1486-1493.

Ródenas, R., Nieves-Cordones, M., Rivero, R.M., Martinez, V., and Rubio, F. (2017). Pharmacological and gene regulation properties point to the SlHAK5 K+ transporter as a system for high-affinity Cs+ uptake in tomato plants. Physiol. Plant. 162(4):455-466.

Růžička, K., Strader, L.C., Bailly, A., Yang, H., Blakeslee, J., Langowski, Ł., Nejedlá, E., Fujita, H., Itoh, H., and Syōno, K. (2010). Arabidopsis PIS1 encodes the ABCG37 transporter of auxinic compounds including the auxin precursor indole-3-butyric acid. Proc. Natl. Acad. Sci. USA 107, 10749-10753.

Schuetz, M., Benske, A., Smith, R.A., Watanabe, Y., Tobimatsu, Y., Ralph, J., Demura, T., Ellis, B., and Samuels, A.L. (2014). Laccases direct lignification in the discrete secondary cell wall domains of protoxylem. Plant Physiol. 166, 798-807.

Shaw, G., and Bell, J. (1991). Competitive effects of potassium and ammonium on caesium uptake kinetics in wheat. J. Environ. Radioact. 13, 283-296.

Shin, J.-L., Lo, J-C., Chen, G.-H., Callis, J., Fu, H., and Yeh, K.-C. (2013). IRT1 DEGRADATION FACTOR1, a RING E3 Ubiquitin Ligase, Regulates the Degradation of IRON-REGULATED TRANSPORTER1 in Arabidopsis. Plant Cell. 25, 3039-3051.

Song, W.-Y., Park, J., Mendoza-Cózatl, D.G., Suter-Grotemeyer, M., Shim, D., Hörtensteiner, S., Geisler, M., Weder, B., Rea, P.A., and Rentsch, D. (2010). Arsenic tolerance in Arabidopsis is mediated by two ABCC-type phytochelatin transporters. Proc. Natl. Acad. Sci. USA 107, 21187-21192.

Swarup, R., and Péret, B. (2012). AUX/LAX family of auxin influx carriers - an overview. Front Plant Sci 3, 225. 
Tate, C.G., Haase, J., Baker, C., Boorsma, M., Magnani, F., Vallis, Y., and Williams, D.C. (2003). Comparison of seven different heterologous protein expression systems for the production of the serotonin transporter. Biochim. Biophys. Acta Biomembranes 1610, 141-153.

Terasaka, K., Blakeslee, J.J., Titapiwatanakun, B., Peer, W.A., Bandyopadhyay, A., Makam, S.N., Lee, O.R., Richards, E.L., Murphy, A.S., and Sato, F. (2005). PGP4, an ATP binding cassette P-glycoprotein, catalyzes auxin transport in Arabidopsis thaliana roots. Plant Cell 17, 2922-2939.

Verrier, P.J., Bird, D., Burla, B., Dassa, E., Forestier, C., Geisler, M., Klein, M., Kolukisaoglu, Ü., Lee, Y., and Martinoia, E. (2008). Plant ABC proteins-a unified nomenclature and updated inventory. Trends Plant Sci. 13, 151-159.

Xu, J., and Scheres, B. (2005). Dissection of Arabidopsis ADP-RIBOSYLATION FACTOR 1 function in epidermal cell polarity. Plant Cell 17, 525-536.

Yamaki, T., Otani, M., Ono, K., Mimura, T., Oda, K., Minamii, T., Matsumoto, S., Matsuo, Y., Kawamukai, M., and Akihiro, T. (2017). Isolation and characterization of rice cesium transporter genes from a rice-transporter-enriched yeast expression library. Physiol. Plant. 160, 425-436.

Yang, H., and Murphy, A. S. (2009). Functional expression and characterization of Arabidopsis ABCB, AUX 1 and PIN auxin transporters in Schizosaccharomyces pombe. Plant J. 59, 179-191.

Zhu, Y.G., and Smolders, E. (2000). Plant uptake of radiocaesium: a review of mechanisms, regulation and application. J. Exp. Bot. 51, 1635-1645.

Zourelidou, M., Absmanner, B., Weller, B., Barbosa, I.C., Willige, B.C., Fastner, A., Streit, V., Port, S.A., Colcombet, J., and van Bentem, S.d.I.F. (2014). Auxin efflux by PINFORMED proteins is activated by two different protein kinases, D6 PROTEIN KINASE and PINOID. Elife 3, e02860.

\section{Figure Legends}

Figure 1. Effect of cesium on Arabidopsis root growth. 
(A) Primary root elongation of wild type (Col-0) in presence of $\mathrm{Cs}^{+}$. Three-day-old light grown wild-type (Col-0) seedlings were transferred to new agar plates with or without cesium $(0.5,1$, 1.5 and $2 \mathrm{mM}$ ) and incubated at $23^{\circ} \mathrm{C}$ for five days. (B) Root phenotype of wild type (Col-0) after three days incubation in control and $1.5 \mathrm{mM} \mathrm{Cs}^{+}$plates. (C) Cortical cell length of wild type (Col-0) after three days incubation in control and $1.5 \mathrm{mM} \mathrm{Cs}^{+}$plates. (D) Cell production rate of wild type (Col-0) after three days incubation in control and $1.5 \mathrm{mM} \mathrm{Cs}^{+}$plates. (E) Effect of cesium on expression of $C y c B 1 ; 1-G U S$ in the primary root tip. (F) Propidium idodide staining of wild type (Col-0). Three-day-old light grown wild type (Col-0) seedlings were transferred to new agar plates with or without $1.5 \mathrm{mM} \mathrm{Cs}^{+}$and observed under confocal microscope at 24, 48 and $72 \mathrm{~h}$ time point. Vertical bars mean $\pm \mathrm{SE}$ from three independent experiments with 8 seedlings observed per experiment $(\mathbf{A}, \mathbf{C}, \mathrm{D})$. Asterisks represent the statistical significance between treatments as judged by student's $t$-test: $* * \mathrm{P}<0.01$ and $* * * \mathrm{P}<0.001$. Images are representative of at least three independent experiments with 5-8 seedlings observed per experiment (B, E, F). Meristem boundary is indicated by arrowheads. Bars $=10 \mathrm{~mm}$ for B and $100 \mu \mathrm{m}$ for $\mathbf{E}$ and $50 \mu \mathrm{m}$ for $\mathbf{F}$.

\section{Figure 2. Gain-of-function mutant, $\operatorname{abcg} 37-1$ shows hypersensitive response to cesium.}

(A) Representative diagram for $A B C G 37$ mutants used in this study. Solid black box and interrupted black line indicate exon and intron, respectively. (B) Primary root growth elongation of Col-0, abcb37-1, abcg37-2, abcg37-3 and abcg37-4 in presence of 1.5 mM Cs ${ }^{+}$. Three-dayold light grown seedlings were transferred to new agar plates with or without $1.5 \mathrm{mM} \mathrm{Cs}^{+}$and incubated at $23^{\circ} \mathrm{C}$ for three days. Vertical bars mean $\pm \mathrm{SE}$ from three independent experiments with 8 seedlings observed per experiment (B). Asterisks represent the statistical significance between treatments as judged by student's $t$-test: ***P $<0.001$ (C) Root phenotype of wild-type

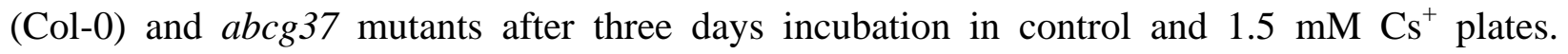
Control phenotype is demonstrated in Figure 1B. Images are representative of at least three independent experiments with 8 seedlings observed per experiment. Bar $=10 \mathrm{~mm}$.

\section{Figure 3. ABCG37 and ABCG33 work redundantly as cesium transporter.}

(A) Root phenotype of wild type (Col-0) and abcg37-2 abcg33-1 -11 after three days incubation in control and $1.5 \mathrm{mM} \mathrm{Cs}^{+}$plates. Images are representative of at least three independent experiments with 8 seedlings observed per experiment. Bar $=10 \mathrm{~mm}$. (B) Primary root elongation 
of Col-0, abcb37-2 abcg33-1-11, abcb37-2 abcg33-1-21 and abcb37-2 abcg33-1-23 in presence of 1, 1.5 and $2 \mathrm{mM} \mathrm{Cs}{ }^{+}$. Three-day-old light grown seedlings were transferred to new agar plates and incubated at $23^{\circ} \mathrm{C}$ for two days. Vertical bars mean $\pm \mathrm{SE}$ from three independent experiments with 8 seedlings observed per experiment. Asterisks represent the statistical significance between treatments as judged by student's $t$-test: $* \mathrm{P}<0.05, * * \mathrm{P}<0.01$ and $* * * \mathrm{P}<0.001$.

\section{Figure 4. Cesium inhibits the expression of ABCG33 and ABCG37.}

Three-day-old light grown ABCG37-GFP and ABCG33-GFP seedlings were transferred to control and $1.5 \mathrm{mM} \mathrm{Cs}^{+}$containing plates. (A) GFP fluorescence of ABCG37-GFP and ABCG33-GFP were observed at 24,48 and $72 \mathrm{~h}$ time point. The images are single confocal sections representative of three independent experiments with 5 seedlings observed per treatment for each experiment. Bars=50 $\mu \mathrm{m}$. (B) Quantification of GFP signal in ABCG37-GFP, ABCG33GFP, PIN2-GFP and EGFP-LTI6b from control and $1.5 \mathrm{mM} \mathrm{Cs}^{+}$containing plates at 24, 48 and $72 \mathrm{~h}$ time point. Quantification was performed from three independent experiments with 5 seedlings observed per treatment for each experiment. Vertical bars mean \pm SE. Asterisks represent the statistical significance between treatments as judged by student's $t$-test: $* \mathrm{P}<0.05$ and $* * * \mathrm{P}<0.001$

\section{Figure 5. ABCG33 and ABCG37 function as cesium influx carriers.}

(A-C) Short term uptake assay of ${ }^{137} \mathrm{Cs}^{+}$in Col-0, abcg37-2 abcg33-1 (11), abcg37-2 abcg33-1 (21) and abcg37-2 abcg33-1 (23) root tip. Four-day-old light grown Col-0, single and double mutant seedlings were incubated for $2 \mathrm{~h}$ at $10 \mu \mathrm{M}, 1.5 \mathrm{mM}, 15 \mathrm{mM}^{137} \mathrm{Cs}^{+}$in presence $(6 \mathrm{mM})$ or absence of $\mathrm{K}^{+}$. After the incubation, seedlings were washed three times and $10 \mathrm{~mm}$ root tip from 10 roots were excised for each sample and radioactivity was counted using a scintillation counter. Data are the averages from at least 3 independent experiments, and expressed as per mm root tip. Vertical bars mean \pm SE. Asterisks represent the statistical significance between genotypes as judged by student's $t$-test: $* \mathrm{P}<0.05$, **P $<0.01$ (D) Cesium content in Col-0 and abcg double mutants. Three-day-old light grown Col-0 and double mutant seedlings were transferred to $1.5 \mathrm{mM} \mathrm{Cs}^{+}$plates in presence of various $\mathrm{K}^{+}$concentrations, and incubated for three days. $\mathrm{Cs}^{+}$ content of whole seedling was measured by ICP-MS. The data were obtained from three independent experiments. Vertical bars mean \pm SE. Asterisks represent the statistical significance between treatments as judged by student's $t$-test: $* \mathrm{P}<0.05$, and $* * \mathrm{P}<0.01$. 
Figure 6. ABCG33 and ABCG37 are potassium-independent cesium transporters.

822 (A) Potassium content in Col-0, abcg37-1, abcg double mutant seedlings. Three-day-old light 823 grown Col-0 and double mutant seedlings were transferred to fresh plates containing various 824 concentrations of $\mathrm{K}^{+}$, and incubated for three days. $\mathrm{K}^{+}$content of whole seedling was measured 825 by ICP-MS. (B) Primary root elongation response of Col-0, abcg33-1 abcg37-2-11, abcg33-1 826 abcg37-2-21 and abcg33-1 abcg37-2-23 in presence of 100mM potassium chloride. Four-day827 old light grown Col-0 and double mutant seedlings were transferred to $100 \mathrm{mM}$ potassium 828 chloride containing plates and incubated for three days. For both (A) and (B) vertical bars mean $829 \pm$ SE from three independent experiments. The $\mathrm{K}^{+}$content and percent root elongation in double 830 mutant are statistically non-significant compared with wild-type as judged by the student's $t$-test. Figure 7. Graphical model of cesium uptake.

832 Schematic representation of current working model of $\mathrm{Cs}^{+}$uptake in Arabidopsis. Left panel 833 demonstrates the typical $\mathrm{Cs}^{+}$uptake inside wild-type (Col-0) cell using various transporters, 834 including $\mathrm{ABC}$ proteins. Right panel shows the loss of ABCG33 and ABCG37 in double 835 knockout mutant resulting in reduced $\mathrm{Cs}^{+}$uptake. $\mathrm{K}^{+}$transporters are presented in red, $\mathrm{ABCG} 33$ 836 in purple, ABCG37 in green and yet unidentified $\mathrm{Cs}^{+}$transporters are in yellow. 
A

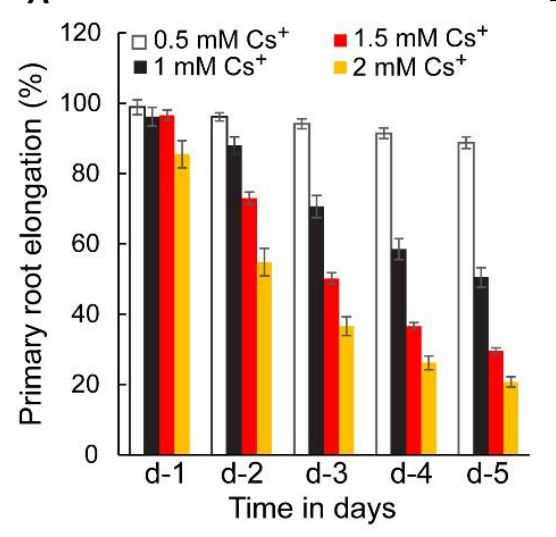

E

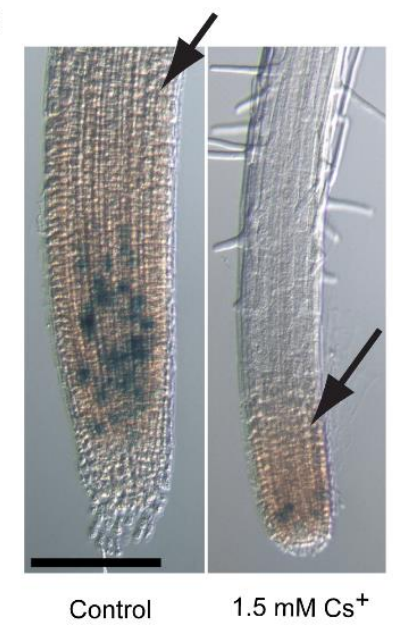

B

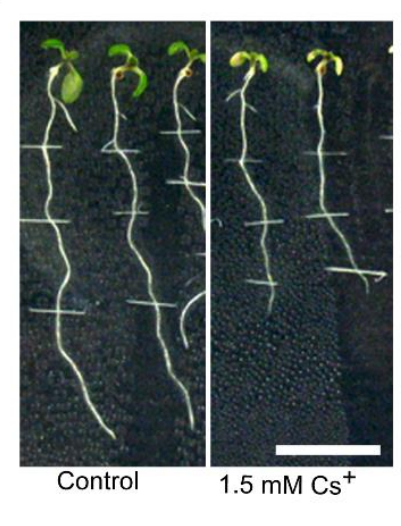

$\mathbf{F}$
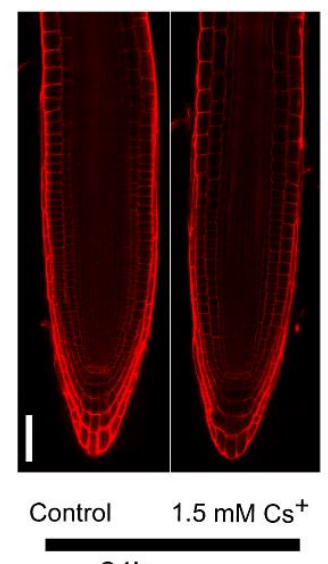

$24 \mathrm{~h}$
C

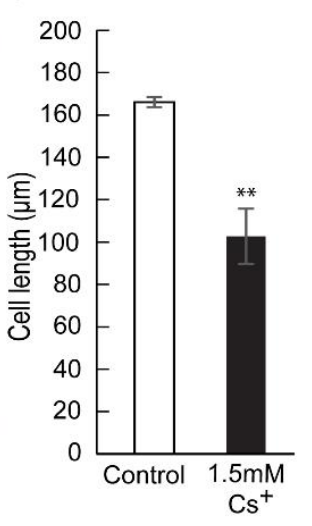

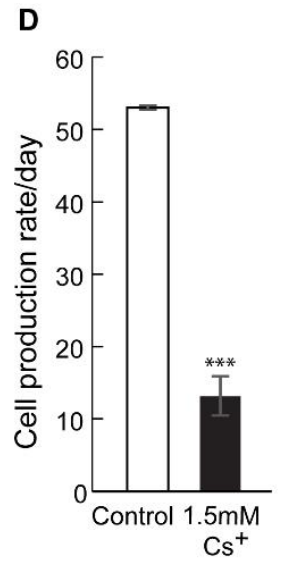

Figure 1. Effect of cesium on Arabidopsis root growth.

(A) Primary root elongation of wild type $(\mathrm{Col}-0)$ in presence of $\mathrm{Cs}^{+}$. Three-day-old light grown wild-type (Col-0) seedlings were transferred to new agar plates with or without cesium $(0.5,1$, 1.5 and $2 \mathrm{mM}$ ) and incubated at $23^{\circ} \mathrm{C}$ for five days. (B) Root phenotype of wild type (Col-0) after three days incubation in control and $1.5 \mathrm{mM} \mathrm{Cs}^{+}$plates. (C) Cortical cell length of wild type (Col-0) after three days incubation in control and $1.5 \mathrm{mM} \mathrm{Cs}^{+}$plates. (D) Cell production rate of wild type (Col-0) after three days incubation in control and $1.5 \mathrm{mM} \mathrm{Cs}^{+}$plates. (E) Effect of cesium on expression of $C y c B 1 ; 1-G U S$ in the primary root tip. (F) Propidium idodide staining of wild type (Col-0). Three-day-old light grown wild type (Col-0) seedlings were transferred to new agar plates with or without $1.5 \mathrm{mM} \mathrm{Cs}^{+}$and observed under confocal microscope at 24, 48 and $72 \mathrm{~h}$ time point. Vertical bars mean $\pm \mathrm{SE}$ from three independent experiments with 8 seedlings observed per experiment (A, C, D). Asterisks represent the statistical significance between treatments as judged by student's $t$-test: $* * \mathrm{P}<0.01$ and $* * * \mathrm{P}<0.001$. Images are representative of at least three independent experiments with 5-8 seedlings observed per experiment $(\mathbf{B}, \mathbf{E}, \mathbf{F})$. Meristem boundary is indicated by arrowheads. Bars $=10 \mathrm{~mm}$ for B and $100 \mu \mathrm{m}$ for $\mathbf{E}$ and $50 \mu \mathrm{m}$ for $\mathbf{F}$. 
A

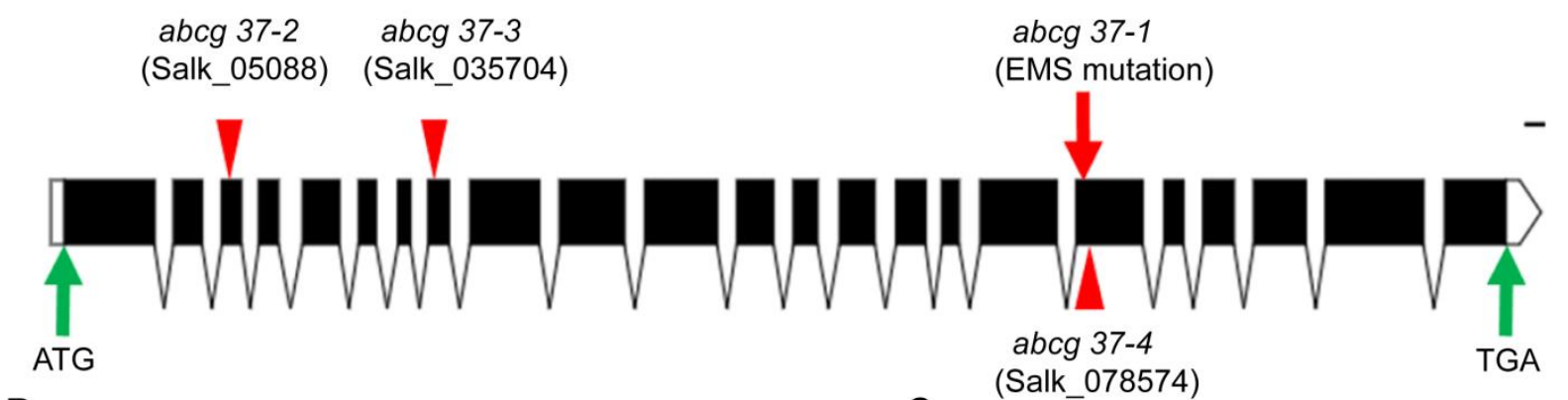

B

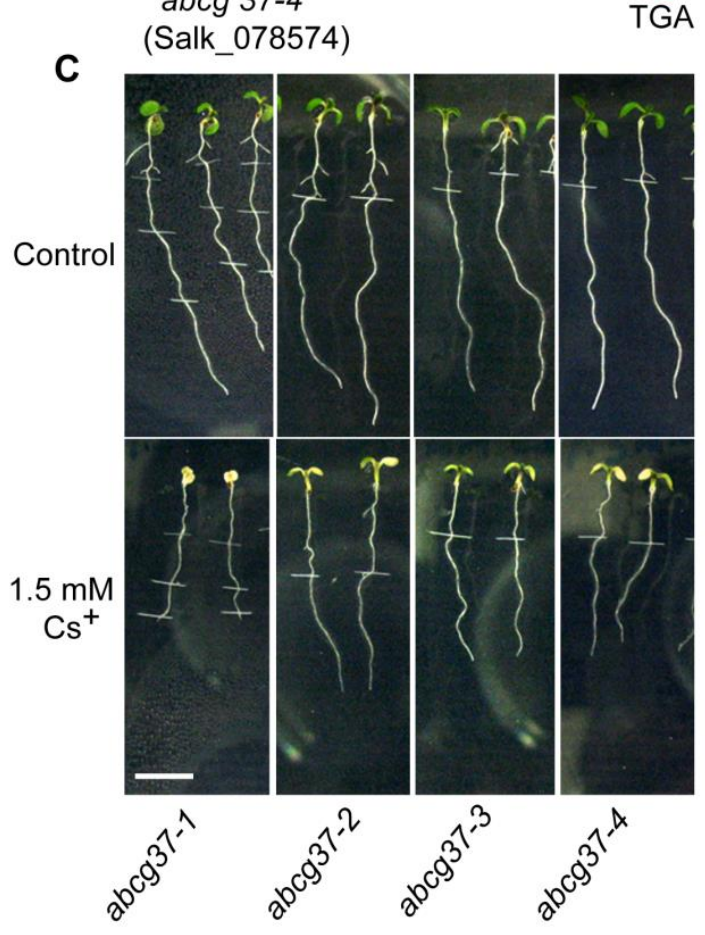

Figure 2. Gain-of-function mutant, $\operatorname{abcg} 37-1$ shows hypersensitive response to cesium.

(A) Representative diagram for $A B C G 37$ mutants used in this study. Solid black box and interrupted black line indicate exon and intron, respectively. (B) Primary root growth elongation of Col-0, abcb37-1, abcg37-2, abcg37-3 and abcg37-4 in presence of 1.5 mM Cs ${ }^{+}$. Three-dayold light grown seedlings were transferred to new agar plates with or without $1.5 \mathrm{mM} \mathrm{Cs}^{+}$and incubated at $23^{\circ} \mathrm{C}$ for three days. Vertical bars mean $\pm \mathrm{SE}$ from three independent experiments with 8 seedlings observed per experiment $(\mathbf{B})$. Asterisks represent the statistical significance between treatments as judged by student's $t$-test: ***P $<0.001$ (C) Root phenotype of wild-type (Col-0) and abcg37 mutants after three days incubation in control and $1.5 \mathrm{mM} \mathrm{Cs}^{+}$plates. Control phenotype is demonstrated in Figure 1B. Images are representative of at least three independent experiments with 8 seedlings observed per experiment. Bar $=10 \mathrm{~mm}$. 
A
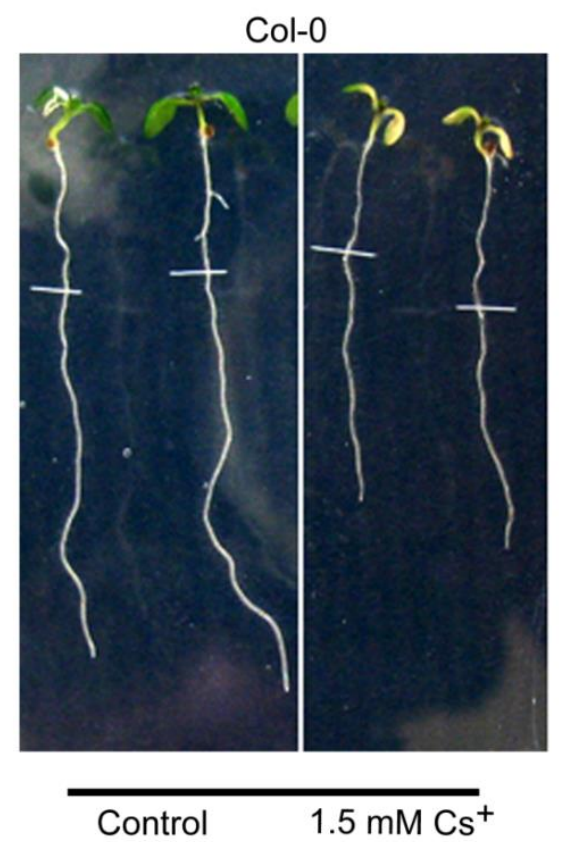

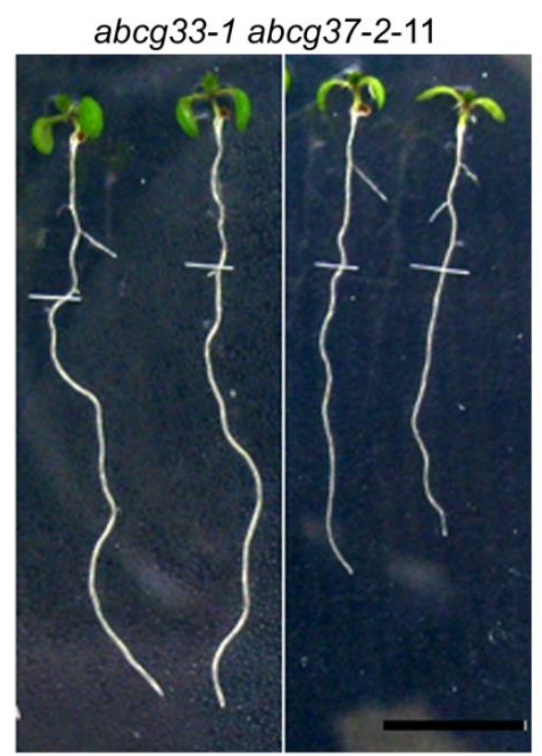

Control

$1.5 \mathrm{mM} \mathrm{Cs}^{+}$

B

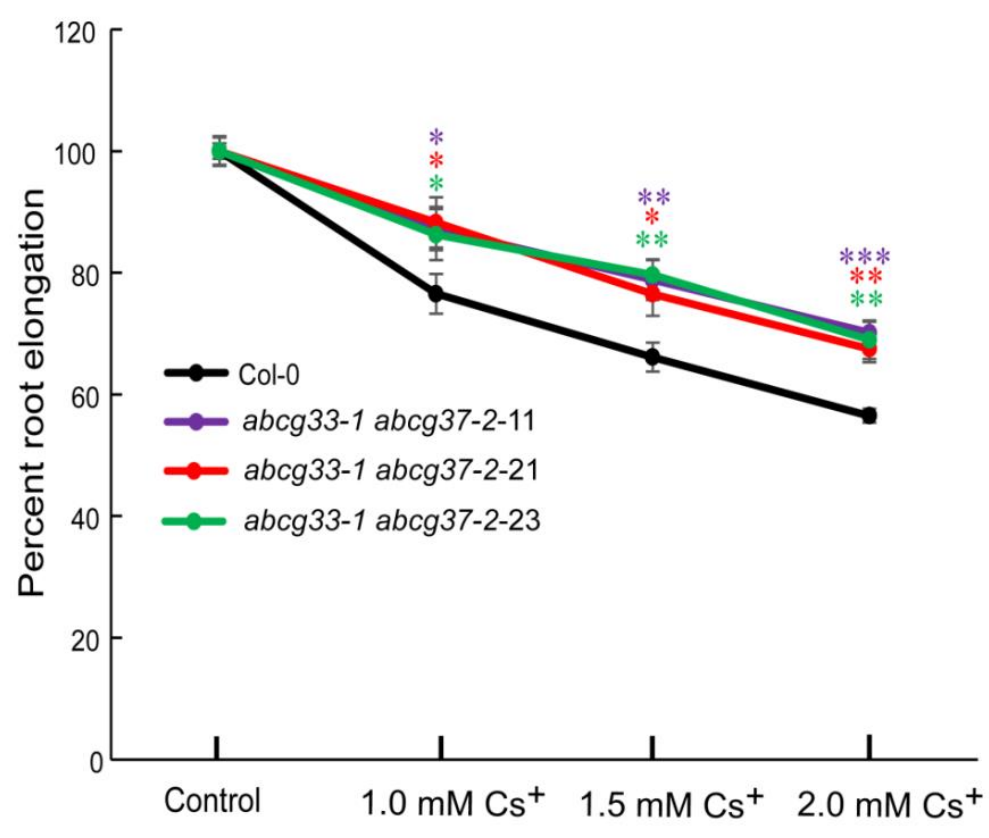

Figure 3.

\section{ABCG37 and ABCG33 work redundantly as cesium transporter.}

\section{(A) Root} phenotype of wild type (Col0) and $a b c g 37$ 2 abcg33-1 -11 after three days incubation in control and 1.5 $\mathrm{mM} \mathrm{Cs}^{+}$plates. Images are representative of at least three independent experiments with 8 seedlings observed per experiment. Bar $=10 \mathrm{~mm}$. (B) Primary root elongation of Col-0, abcb37-2 abcg33-1-11, abcb37-2 abcg33-1-21 and $a b c b 37-2$ abcg33-1-23 in

presence of 1, 1.5 and $2 \mathrm{mM} \mathrm{Cs}^{+}$. Three-day-old light grown seedlings were transferred to new agar plates and incubated at $23^{\circ} \mathrm{C}$ for two days. Vertical bars mean \pm SE from three independent experiments with 8 seedlings observed per experiment. Asterisks represent the statistical significance between treatments as judged by student's $t$-test: $* \mathrm{P}<0.05$, **P $<0.01$ and $* * * \mathrm{P}<$ 0.001 . 


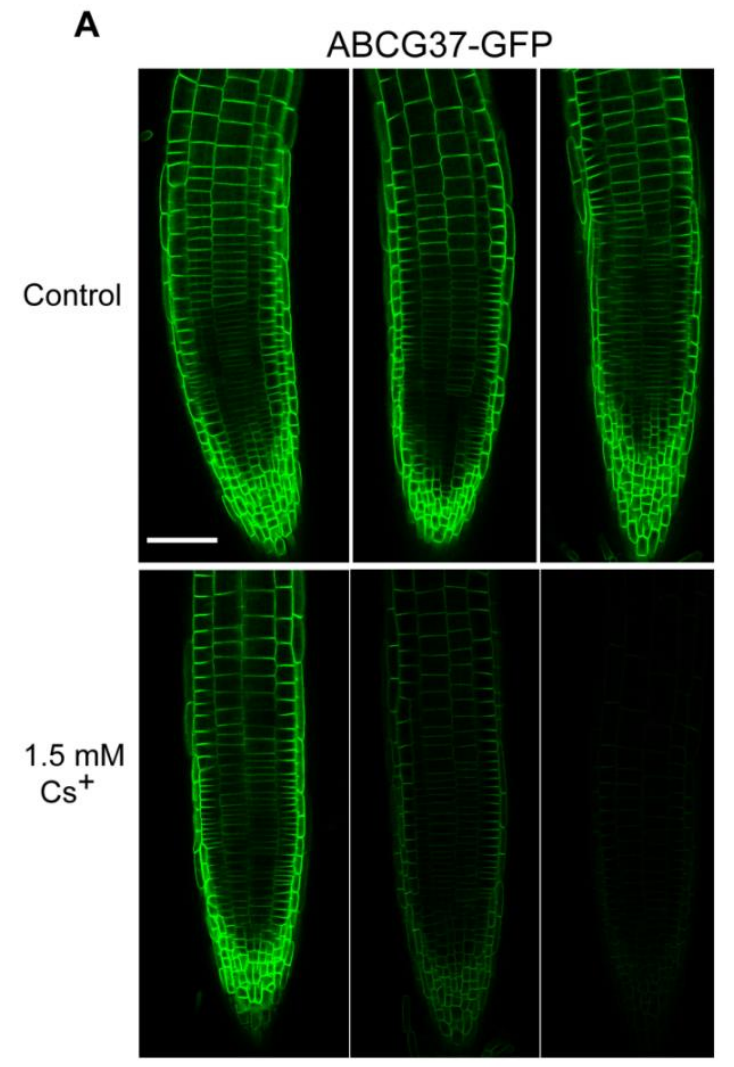

$24 \mathrm{~h}$

B

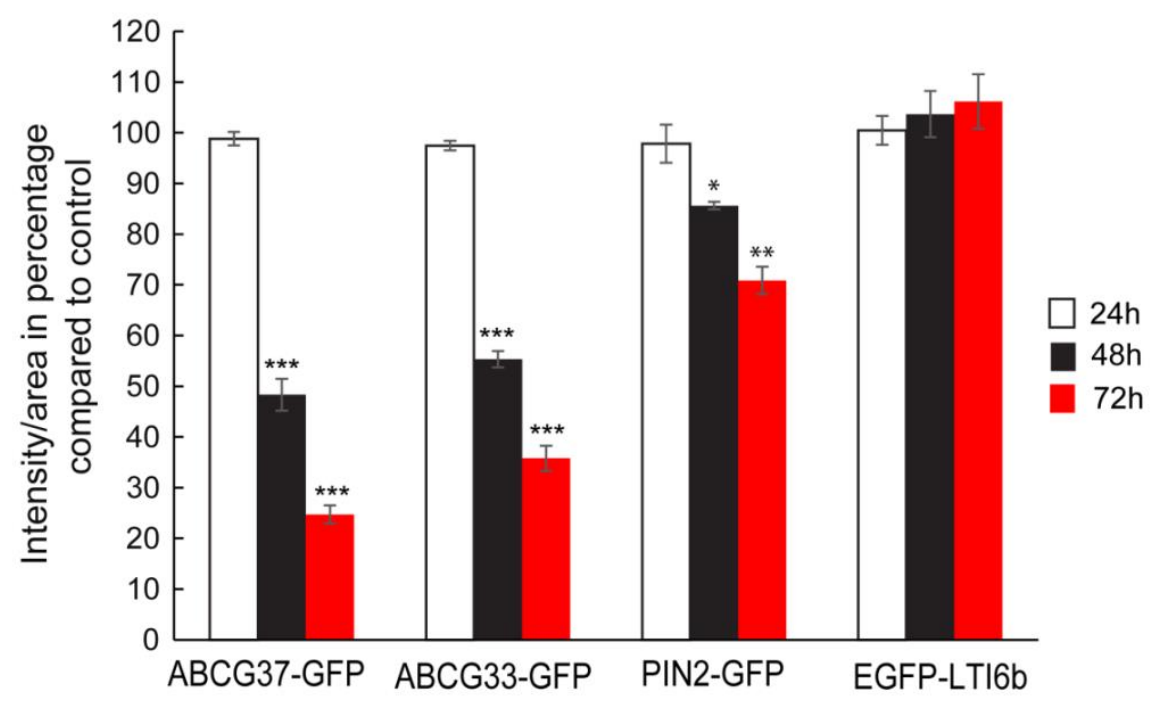

ABCG33-GFP

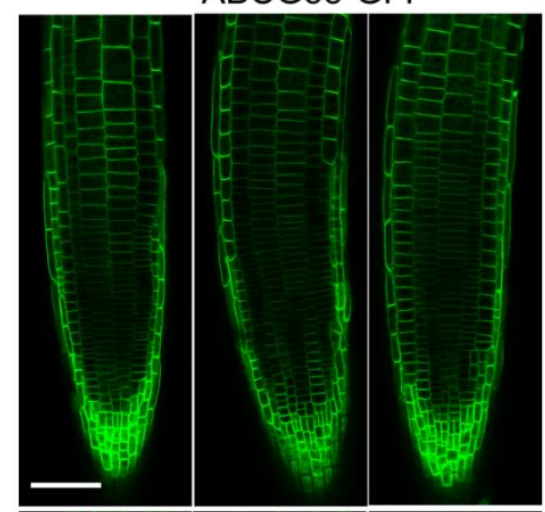

$72 \mathrm{~h}$

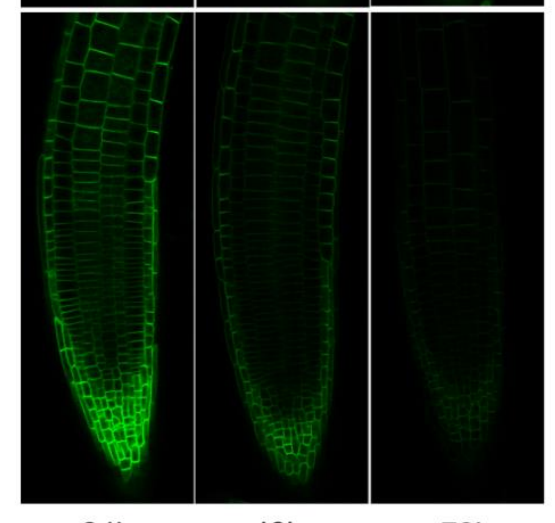

Figure 4.

Cesium

inhibits the

expression of

ABCG33 and

ABCG37.

Three-day-old

light grown

ABCG37-GFP

and ABCG33-

GFP seedlings

were transferred

to control and

$1.5 \mathrm{mM} \mathrm{Cs}^{+}$

containing

plates. (A) GFP

fluorescence of

ABCG37-GFP

and ABCG33-

GFP were

observed at 24 ,

48 and $72 \mathrm{~h}$ time

point. The

images are

single confocal

sections

representative

of three

independent

experiments

with 5 seedlings

observed per

treatment for

each experiment.

Bars $=50 \mu \mathrm{m}$. (B)

Quantification

of GFP signal in ABCG37-GFP, ABCG33-GFP, PIN2-GFP and EGFP-LTI6b from control and $1.5 \mathrm{mM} \mathrm{Cs}^{+}$containing plates at 24,48 and $72 \mathrm{~h}$ time point. Quantification was performed from three independent experiments with 5 seedlings observed per treatment for each experiment. Vertical bars mean \pm SE. Asterisks represent the statistical significance between treatments as judged by student's $t$-test: $* \mathrm{P}<0.05$ and $* * * \mathrm{P}<0.001$. 

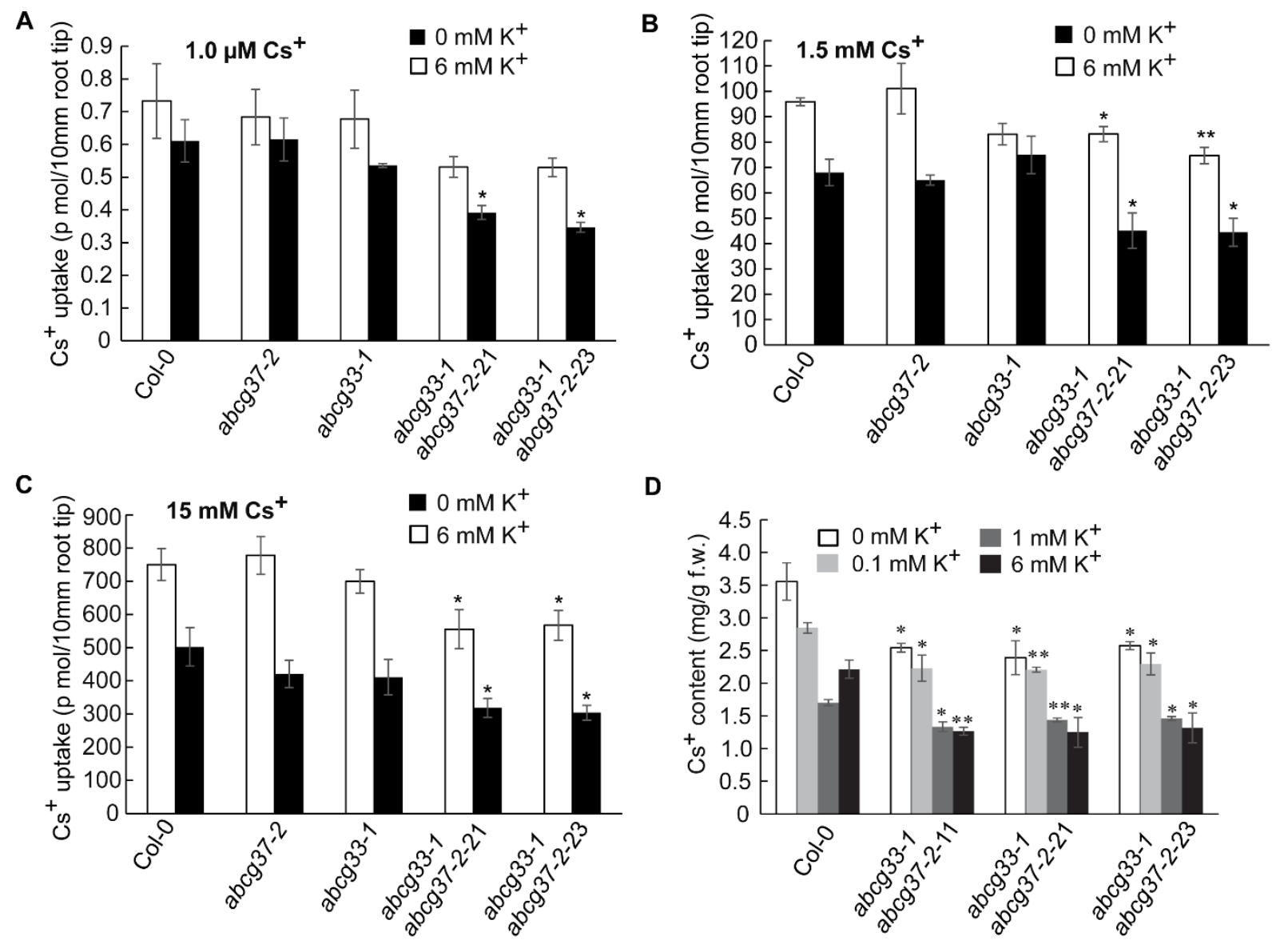

D

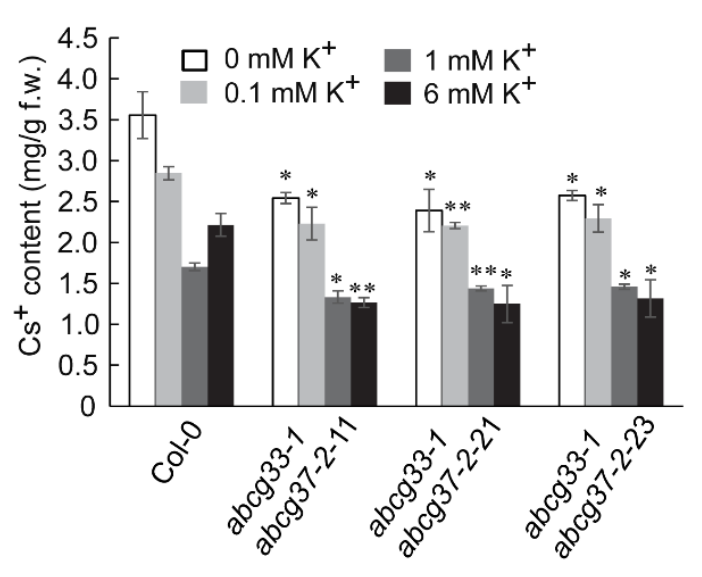

Figure 5. ABCG33 and ABCG37 function as cesium influx carriers.

(A-C) Short term uptake assay of ${ }^{137} \mathrm{Cs}^{+}$in Col-0, abcg37-2 abcg33-1 (11), abcg37-2 abcg33-1 (21) and abcg37-2 abcg33-1 (23) root tip. Four-day-old light grown Col-0, single and double mutant seedlings were incubated for $2 \mathrm{~h}$ at $10 \mu \mathrm{M}, 1.5 \mathrm{mM}, 15 \mathrm{mM}^{137} \mathrm{Cs}^{+}$in presence $(6 \mathrm{mM})$ or absence of $\mathrm{K}^{+}$. After the incubation, seedlings were washed three times and $10 \mathrm{~mm}$ root tip from 10 roots were excised for each sample and radioactivity was counted using a scintillation counter. Data are the averages from at least 3 independent experiments, and expressed as per mm root tip. Vertical bars mean \pm SE. Asterisks represent the statistical significance between genotypes as judged by student's $t$-test: $* \mathrm{P}<0.05$, **P $<0.01$ (D) Cesium content in Col-0 and abcg double mutants. Three-day-old light grown Col-0 and double mutant seedlings were transferred to $1.5 \mathrm{mM} \mathrm{Cs}^{+}$plates in presence of various $\mathrm{K}^{+}$concentrations, and incubated for three days. $\mathrm{Cs}^{+}$ content of whole seedling was measured by ICP-MS. The data were obtained from three independent experiments. Vertical bars mean \pm SE. Asterisks represent the statistical significance between treatments as judged by student's $t$-test: $* \mathrm{P}<0.05$, and $* * \mathrm{P}<0.01$. 
A

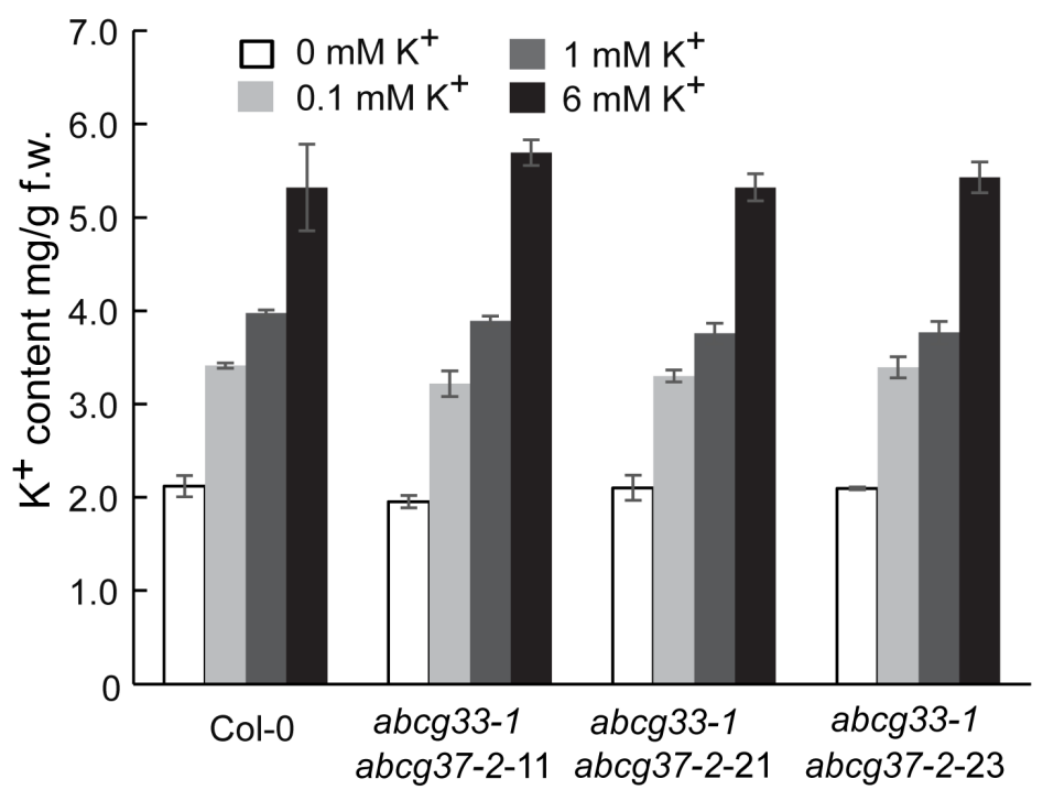

B

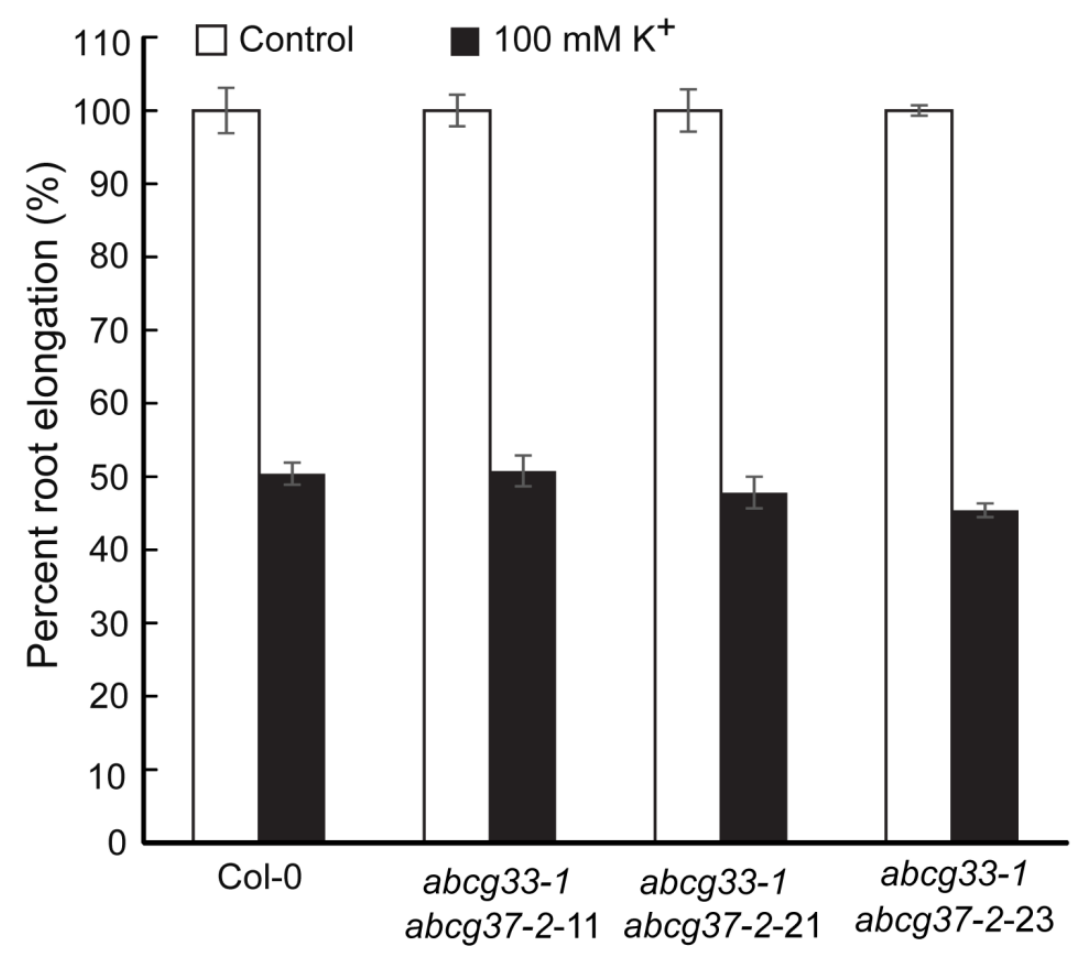

Figure 6.

ABCG33 and

ABCG37 are

potassium-

independent

cesium

transporters.

(A) Potassium content in Col-0, abcg37-1, abcg double mutant seedlings. Threeday-old light grown Col-0 and double mutant seedlings were transferred to fresh plates containing various concentrations of $\mathrm{K}^{+}$, and incubated for three days. $\mathrm{K}^{+}$ content of whole seedling was measured by ICPMS. (B) Primary root elongation response of Col-0, abcg33-1 abcg372-11, abcg33-1 abcg37-2-21 and abcg33-1 abcg372-23 in presence of $100 \mathrm{mM}$ potassium chloride. Four-dayold light grown Col-0 and double mutant seedlings were transferred to

$100 \mathrm{mM}$ potassium chloride containing plates and incubated for three days. For both (A) and (B) vertical bars mean $\pm \mathrm{SE}$ from three independent experiments. The $\mathrm{K}^{+}$content and percent root elongation in double mutant are statistically non-significant compared with wild-type as judged by the student's $t$-test. 


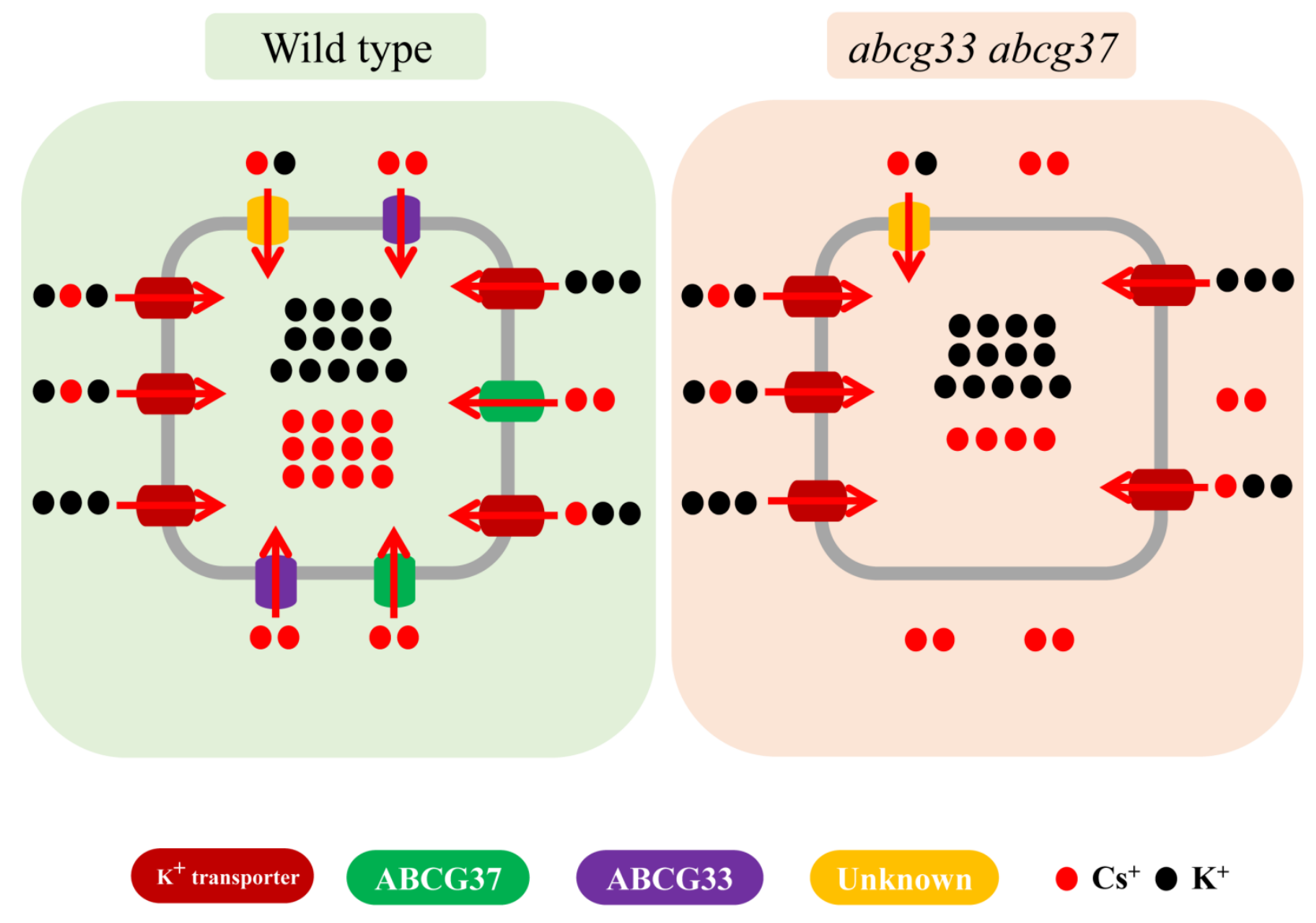

Figure 7. Graphical model of cesium uptake.

Schematic representation of current working model of $\mathrm{Cs}^{+}$uptake in Arabidopsis. Left panel demonstrates the typical $\mathrm{Cs}^{+}$uptake inside wild-type (Col-0) cell using various transporters, including $\mathrm{ABC}$ proteins. Right panel shows the loss of ABCG33 and ABCG37 in double knockout mutant resulting in reduced $\mathrm{Cs}^{+}$uptake. $\mathrm{K}^{+}$transporters are presented in red, ABCG33 in purple, $\mathrm{ABCG} 37$ in green and yet unidentified $\mathrm{Cs}^{+}$transporters are in yellow. 


\section{Parsed Citations}

Baskin, T.I., and Wilson, J.E. (1997). Inhibitors of protein kinases and phosphatases alter root morphology and disorganize cortical microtubules. Plant Physiol. 113, 493-502.

Pubmed: Author and Title

Google Scholar: Author Only Title Only Author and Title

Bernaudat, F., Frelet-Barrand, A, Pochon, N., Dementin, S., Hivin, P., Boutigny, S., Rioux, J.-B., Salvi, D., Seigneurin-Berny, D., and Richaud, P. (2011). Heterologous expression of membrane proteins: choosing the appropriate host. PloS one 6, e29191.

Pubmed: Author and Title

Google Scholar: Author Only Title Only Author and Title

Bonander, N., Hedfalk, K., Larsson, C., Mostad, P., Chang, C., Gustafsson, L., and Bill, R.M. (2005). Design of improved membrane protein production experiments: quantitation of the host response. Protein Sci. 14, 1729-1740.

Pubmed: Author and Title

Google Scholar: Author Only Title Only Author and Title

Cho, M., Lee, S.H., and Cho, H.-T. (2007). P-Glycoprotein4 displays auxin efflux transporter-like action in Arabidopsis root hair cells and tobacco cells. The Plant Cell 19, 3930-3943.

Pubmed: Author and Title

Google Scholar: Author Only Title Only Author and Title

Collander, R. (1941). Selective absorption of cations by higher plants. Plant Physiol. 16, 691.

Pubmed: Author and Title

Google Scholar: Author Only Title Only Author and Title

Colón-Carmona, A, You, R., Haimovitch-Gal, T., and Doerner, P. (1999). Spatio-temporal analysis of mitotic activity with a labile cyclinGUS fusion protein. Plant J. 20, 503-508.

Pubmed: Author and Title

Google Scholar: Author Only Title Only Author and Title

Cooghtrey, P., Jackson, D., and Thorne, M. (1983). Radionuclide distribution and transport in terrestrial and aquatic ecosystems: A critical review of data: CRC press.

Dreyer, I., Horeau, C., Lemaillet, G., Zmmermann, S., Bush, D.R., Rodríguez-Navarro, A, Schachtman, D.P., Spalding, E.P., Sentenac, H., and Gaber, R.F. (1999). Identification and characterization of plant transporters using heterologous expression systems. J. Exp.

Bot. 50,1073-1087.

Pubmed: Author and Title

Google Scholar: Author Only Title Only Author and Title

Dubeaux, G., Neveu, J., Zelazny, E., and Vert, G. (2018). Metal sensing by the IRT1 transporter-receptor orchestrates its own degradation and plant metal nutrition. Mol.Cell. 69, 953-964.

Pubmed: Author and Title

Google Scholar: Author Only Title Only Author and Title

Formentin, E., Varotto, S., Costa, A, Downey, P., Bregante, M., Naso, A, Picco, C., Gambale, F., and Lo Schiavo, F. (2004). DKT1, a novel K+ channel from carrot, forms functional heteromeric channels with KDC1. FEBS Lett. 573, 61-67.

Pubmed: Author and Title

Google Scholar: Author Only Title Only Author and Title

Fourcroy, P., Sisó-Terraza, P., Sudre, D., Savirón, M., Reyt, G., Gaymard, F., Abadía, A, Abadia, J., Álvarez-Fernández, A, and Briat, J.F. (2014). Involvement of the ABCG37 transporter in secretion of scopoletin and derivatives by Arabidopsis roots in response to iron deficiency. New Phytol. 201, 155-167.

Pubmed: Author and Title

Google Scholar: Author Only Title Only Author and Title

Fujiwara, T. (2013). Cesium uptake in rice: possible transporter, distribution, and variation. In Agricultural Implications of the Fukushima Nuclear Accident (Springer), pp. 29-35.

Pubmed: Author and Title

Google Scholar: Author Only Title Only Author and Title

Gaymard, F., Cerutti, M., Horeau, C., Lemaillet, G., Urbach, S., Ravallec, M., Devauchelle, G., Sentenac, H., and Thibaud, J.-B. (1996). The Baculovirus/Insect Cell System as an Aternative to Xenopus Oocytes first characterization of the AKT1 K+ channel from Arabidopsis thaliana. J. Biol. Chem. 271, 22863-22870.

Pubmed: Author and Title

Google Scholar: Author Only Title Only Author and Title

Griffith, D.A, Delipala, C., Leadsham, J., Jarvis, S.M., and Oesterhelt, D. (2003). A novel yeast expression system for the overproduction of quality-controlled membrane proteins. FEBS Lett. 553, 45-50.

Pubmed: Author and Title

Google Scholar: Author Only Title Only Author and Title

Hampton, C.R., Bowen, H.C., Broadley, M.R., Hammond, J.P., Mead, A, Payne, K.A, Pritchard, J., and White, P.J. (2004). Cesium toxicity in Arabidopsis. Plant Physiol. 136, 3824-3837. 
Google Scholar: Author Only Title Only Author and Title

Hanzawa, T., Shibasaki, K., Numata, T., Kawamura, Y., Gaude, T., and Rahman, A (2013). Cellular auxin homeostasis under high temperature is regulated through a SORTING NEXIN1-dependent endosomal trafficking pathway. Plant Cell 25, $3424-3433$.

Pubmed: Author and Title

Google Scholar: Author Only Title Only Author and Title

Isaure, M.-P., Fraysse, A, Deves, G., Le Lay, P., Fayard, B., Susini, J., Bourguignon, J., and Ortega, R. (2006). Micro-chemical imaging of cesium distribution in Arabidopsis thaliana plant and its interaction with potassium and essential trace elements. Biochimie 88, 15831590.

Pubmed: Author and Title

Google Scholar: Author Only Title Only Author and Title

Ishikawa, S., Hayashi, S., Abe, T., Igura, M., Kuramata, M., Tanikawa, H., lino, M., Saito, T., Ono, Y., and Ishikawa, T. (2017). Low-cesium rice: mutation in OsSOS2 reduces radiocesium in rice grains. Sci Rep 7, 2432.

Pubmed: Author and Title

Google Scholar: Author Only Title Only Author and Title

Ito, H., and Gray, W.M. (2006). Again-of-function mutation in the Arabidopsis pleiotropic drug resistance transporter PDR9 confers resistance to auxinic herbicides. Plant Physiol. 142, 63-74.

Pubmed: Author and Title

Google Scholar: Author Only Title Only Author and Title

Jung, I.L., Ryu, M., Cho, S.K., Shah, P., Lee, J.H., Bae, H., Kim, I.G., and Yang, S.W. (2015). Cesium toxicity alters MicroRNA processing and AGO1 expressions in Arabidopsis thaliana. PloS one 10, e 0125514.

Pubmed: Author and Title

Google Scholar: Author Only Title Only Author and Title

Kang, J., Hwang, J-U., Lee, M., Kim, Y-Y., Assmann, S.M., Martinoia, E., and Lee, Y. (2010). PDR-type ABC transporter mediates cellular uptake of the phytohormone abscisic acid. Proc. Natl. Acad. Sci. USA 107, 2355-2360.

Pubmed: Author and Title

Google Scholar: Author Only Title Only Author and Title

Kanter, U., Hauser, A, Michalke, B., Dräxl, S., and Schäffner, AR. (2010). Caesium and strontium accumulation in shoots of Arabidopsis thaliana: genetic and physiological aspects. J. Exp. Bot. 61, 3995-4009.

Pubmed: Author and Title

Google Scholar: Author Only Title Only Author and Title

Kim, D.-Y., Bovet, L., Kushnir, S., Noh, E.W., Martinoia, E., and Lee, Y. (2006). AtATM3 is involved in heavy metal resistance in Arabidopsis. Plant Physiol. 140, 922-932.

Pubmed: Author and Title

Google Scholar: Author Only Title Only Author and Title

Kim, D.Y., Bovet, L., Maeshima, M., Martinoia, E., and Lee, Y. (2007). The ABC transporter AtPDR8 is a cadmium extrusion pump conferring heavy metal resistance. Plant J. 50, 207-218.

Pubmed: Author and Title

Google Scholar: Author Only Title Only Author and Title

Kobayashi, D., Uozumi, N., HISAMATSU, S.i., and Yamagami, M. (2010). AtKUP/HAK/KT9, a K+ transporter from Arabidopsis thaliana, mediates Cs+ uptake in Escherichia coli. Biosci., Biotechnol., Biochem. 74, 203-205.

Pubmed: Author and Title

Google Scholar: Author Only Title Only Author and Title

Kubeš, M., Yang, H., Richter, G.L., Cheng, Y., Młodzińska, E., Wang, X., Blakeslee, J.J., Carraro, N., Petrášek, J., and Zažímalová, E. (2012). The Arabidopsis concentration-dependent influx/efflux transporter ABCB4 regulates cellular auxin levels in the root epidermis. Plant J. 69, 640-654.

Pubmed: Author and Title

Google Scholar: Author Only Title Only Author and Title

Kurup, S., Runions, J., Köhler, U., Laplaze, L., Hodge, S., and Haseloff, J. (2005). Marking cell lineages in living tissues. Plant J. 42, 444453.

Pubmed: Author and Title

Google Scholar: Author Only Title Only Author and Title

Lee, M., Lee, K., Lee, J., Noh, E.W., and Lee, Y. (2005). AtPDR12 contributes to lead resistance in Arabidopsis. Plant Physiol. 138, 827836.

Pubmed: Author and Title

Google Scholar: Author Only Title Only Author and Title

Lenoir, G., Menguy, T., Corre, F., Montigny, C., Pedersen, P.A, Thinès, D., le Maire, M., and Falson, P. (2002). Overproduction in yeast and rapid and efficient purification of the rabbit SERCA1a Ca 2+-ATPase. Biochim. Biophys. Acta Biomembranes 1560, 67-83.

Pubmed: Author and Title

Google Scholar: Author Only Title Only Author and Title 
Li, W., Ma, M., Feng, Y., Li, H., Wang, Y., Ma, Y., Li, M., An, F., and Guo, H. (2015). ElN2-directed translational regulation of ethylene signaling in Arabidopsis. Cell 163, 670-683.

Pubmed: Author and Title

Google Scholar: Author Only Title Only Author and Title

Ma, J.F., Yamaji, N., Mitani, N., Xu, X.-Y., Su, Y.-H., McGrath, S.P., and Zhao, F.-J. (2008). Transporters of arsenite in rice and their role in arsenic accumulation in rice grain. Proc. Natl. Acad. Sci. USA105, 9931-9935.

Pubmed: Author and Title

Google Scholar: Author Only Title Only Author and Title

Merchante, C., Brumos, J., Yun, J., Hu, Q., Spencer, K.R., Enríquez, P., Binder, B.M., Heber, S., Stepanova, AN., and Alonso, J.M. (2015). Gene-specific translation regulation mediated by the hormone-signaling molecule EIN2. Cell 163, 684-697.

Pubmed: Author and Title

Google Scholar: Author Only Title Only Author and Title

Midgett, C.R., and Madden, D.R. (2007). Breaking the bottleneck: eukaryotic membrane protein expression for high-resolution structural studies. J. Struct. Biol. 160, 265-274.

Pubmed: Author and Title

Google Scholar: Author Only Title Only Author and Title

Nieves-Cordones, M., Mohamed, S., Tanoi, K., Kobayashi, N.I., Takagi, K., Vernet, A, Guiderdoni, E., Périn, C., Sentenac, H., and Véry, AA (2017). Production of low-Cs+ rice plants by inactivation of the K+ transporter OsHAK1 with the CRISPR-Cas system Plant J. 92: 43-56.

Pubmed: Author and Title

Google Scholar: Author Only Title Only Author and Title

Okamoto, T., Tsurumi, S., Shibasaki, K., Obana, Y., Takaji, H., Oono, Y., and Rahman, A (2008). Genetic dissection of hormonal responses in the roots of Arabidopsis grown under continuous mechanical impedance. Plant Physiol. 146, $1651-1662$.

Pubmed: Author and Title

Google Scholar: Author Only Title Only Author and Title

Park, J., Song, W.Y., Ko, D., Eom, Y., Hansen, T.H., Schiller, M., Lee, T.G., Martinoia, E., and Lee, Y. (2012). The phytochelatin transporters AtABCC1 and AtABCC2 mediate tolerance to cadmium and mercury. Plant J. 69, 278-288.

Pubmed: Author and Title

Google Scholar: Author Only Title Only Author and Title

Rahman, A, Bannigan, A, Sulaman, W., Pechter, P., Blancaflor, E.B., and Baskin, T.I. (2007). Auxin, actin and growth of the Arabidopsis thaliana primary root. Plant J. 50, 514-528.

Pubmed: Author and Title

Google Scholar: Author Only Title Only Author and Title

Rai, H., Yokoyama, S., Satoh-Nagasawa, N., Furukawa, J., Nomi, T., Ito, Y., Fujimura, S., Takahashi, H., Suzuki, R., and Yousra, E. (2017). Cesium Uptake by Rice Roots Largely Depends Upon a Single Gene, HAK1, Which Encodes a Potassium Transporter. Plant Cell

Physiol. 58, 1486-1493.

Pubmed: Author and Title

Google Scholar: Author Only Title Only Author and Title

Ródenas, R., Nieves-Cordones, M., Rivero, R.M., Martinez, V., and Rubio, F. (2017). Pharmacological and gene regulation properties point to the SIHAK5 K+ transporter as a system for high-affinity Cs+ uptake in tomato plants. Physiol. Plant. 162(4):455-466.

Pubmed: Author and Title

Google Scholar: Author Only Title Only Author and Title

Růžička, K., Strader, L.C., Bailly, A, Yang, H., Blakeslee, J., Łangowski, Ł., Nejedlá, E., Fujita, H., Itoh, H., and Syōno, K. (2010). Arabidopsis PIS1 encodes the ABCG37 transporter of auxinic compounds including the auxin precursor indole-3-butyric acid. Proc. Natl. Acad. Sci. USA 107, 10749-10753.

Pubmed: Author and Title

Google Scholar: Author Only Title Only Author and Title

Schuetz, M., Benske, A, Smith, R.A, Watanabe, Y., Tobimatsu, Y., Ralph, J., Demura, T., Ellis, B., and Samuels, AL. (2014). Laccases direct lignification in the discrete secondary cell wall domains of protoxylem. Plant Physiol. 166, 798-807.

Pubmed: Author and Title

Google Scholar: Author Only Title Only Author and Title

Shaw, G., and Bell, J. (1991). Competitive effects of potassium and ammonium on caesium uptake kinetics in wheat. J. Environ.

Radioact. 13, 283-296.

Pubmed: Author and Title

Google Scholar: Author Only Title Only Author and Title

Shin, J.-L., Lo, J-C., Chen, G.-H., Callis, J., Fu, H., and Yeh, K.-C. (2013). IRT1 DEGRADATION FACTOR1, a RING E3 Ubiquitin Ligase, Regulates the Degradation of IRON-REGULATED TRANSPORTER1 in Arabidopsis. Plant Cell. 25, 3039-3051.

Pubmed: Author and Title

Google Scholar: Author Only Title Only Author and Title

Song, W.-Y., Park, J., Mendoza-Cózatl, D.G., Suter-Grotemeyer, M., Shim, D., Hörtensteiner, S., Geisler, M., Weder, B., Rea, P.A, and 
Rentsch, D. (2010). Arsenic tolerance in Arabidopsis is mediated by two ABCC-type phytochelatin transporters. Proc. Natl. Acad. Sci. USA 107, 21187-21192.

Pubmed: Author and Title

Google Scholar: Author Only Title Only Author and Title

Swarup, R., and Péret, B. (2012). AUX/LAX family of auxin influx carriers-an overview. Front Plant Sci 3, 225.

Pubmed: Author and Title

Google Scholar: Author Only Title Only Author and Title

Tate, C.G., Haase, J., Baker, C., Boorsma, M., Magnani, F., Vallis, Y., and Williams, D.C. (2003). Comparison of seven different heterologous protein expression systems for the production of the serotonin transporter. Biochim Biophys. Acta Biomembranes 1610, 141-153.

Pubmed: Author and Title

Google Scholar: Author Only Title Only Author and Title

Terasaka, K., Blakeslee, J.J., Titapiwatanakun, B., Peer, W.A, Bandyopadhyay, A, Makam, S.N., Lee, O.R., Richards, E.L., Murphy, AS., and Sato, F. (2005). PGP4, an ATP binding cassette P-glycoprotein, catalyzes auxin transport in Arabidopsis thaliana roots. Plant Cell 17, 2922-2939.

Pubmed: Author and Title

Google Scholar: Author Only Title Only Author and Title

Verrier, P.J., Bird, D., Burla, B., Dassa, E., Forestier, C., Geisler, M., Klein, M., Kolukisaoglu, Ü., Lee, Y., and Martinoia, E. (2008). Plant ABC proteins-a unified nomenclature and updated inventory. Trends Plant Sci. 13, 151-159.

Pubmed: Author and Title

Google Scholar: Author Only Title Only Author and Title

Xu, J., and Scheres, B. (2005). Dissection of Arabidopsis ADP-RIBOSYLATION FACTOR 1 function in epidermal cell polarity. Plant Cell 17, 525-536.

Pubmed: Author and Title

Google Scholar: Author Only Title Only Author and Title

Yamaki, T., Otani, M., Ono, K., Mimura, T., Oda, K., Minamii, T., Matsumoto, S., Matsuo, Y., Kawamukai, M., and Akihiro, T. (2017). Isolation and characterization of rice cesium transporter genes from a rice-transporter-enriched yeast expression library. Physiol. Plant. 160, 425-436.

Pubmed: Author and Title

Google Scholar: Author Only Title Only Author and Title

Yang, H., and Murphy, A S. (2009). Functional expression and characterization of Arabidopsis ABCB, AUX 1 and PIN auxin transporters in Schizosaccharomyces pombe. Plant J. 59, 179-191.

Pubmed: Author and Title

Google Scholar: Author Only Title Only Author and Title

Zhu, Y.G., and Smolders, E. (2000). Plant uptake of radiocaesium: a review of mechanisms, regulation and application. J. Exp. Bot. 51, 1635-1645.

Pubmed: Author and Title

Google Scholar: Author Only Title Only Author and Title

Zourelidou, M., Absmanner, B., Weller, B., Barbosa, I.C., Willige, B.C., Fastner, A, Streit, V., Port, S.A, Colcombet, J., and van Bentem, S.d.I.F. (2014). Auxin efflux by PIN-FORMED proteins is activated by two different protein kinases, D6 PROTEIN KINASE and PINOID. Elife 3, e02860.

Pubmed: Author and Title

Google Scholar: Author Only Title Only Author and Title 